\title{
Simulación de recuperación de plusvalía urbana para Línea 3 del Metro de Santiago
}

\author{
Francisco Vergara-Perucich ${ }^{1}$ | Carlos Aguirre-Núñez ${ }^{2}$
}

Recibido: 02-10-2019 | en su versión final: 22-01-2020

Resumen

\begin{abstract}
El presente artículo corresponde a una simulación de recuperación de plusvalías aplicado sobre las transacciones de suelo y de departamentos nuevos para 40 casos ubicados cerca de la nueva línea 3 de Metro de Santiago. En Chile, la recuperación de plusvalías no existe como política pública, aunque diferentes actores han instalado el debate de evaluar su implementación ante diversos anuncios sobre nuevas líneas de metro en la Región Metropolitana de Santiago. La principal razón de este artículo es aportar al debate con datos empíricos sobre las potenciales consecuencias de aplicar estos instrumentos para líneas de metro, tomando como referencia los modelos de recuperación de plusvalía en Colombia. Con esta simulación, el estudio ensaya las propuestas de Martim Smolka para recuperación de plusvalías en naciones de América Latina con el fin de mejorar la provisión de fondos fiscales y mejorar los entornos urbanos. En Chile, este ejercicio no se ha realizado aún, aunque existen contribuciones similares que desde diferentes enfoques ponen en valor los resultados que surgen del presente estudio. La metodología es cuantitativa, con carácter exploratorio y de orden inductivo, usando la medición de rentabilidad por VAN a partir de un levantamiento histórico del proyecto, sus valores, el precio de suelo y sus tipologías, para aplicar una captura de valor del $50 \%$ para las ganancias de terrenos y de $30 \%$ de los departamentos. Los hallazgos dan cuenta de una buena posibilidad de recaudación pero que requiere de ajustes específicos para que estos instrumentos no impidan que el mercado de la vivienda se vuelva insolvente.
\end{abstract}

Palabras clave: Inversión pública; desigualdad; Chile; economía urbana; rentabilidad inmobiliaria

Citación

Vergara-Perucich, F. y Aguirre-Núñez, C. (2020). Simulación de recuperación de plusvalía urbana para Línea 3 del Metro de Santiago, ACE: Architecture, City and Environment, 14(42), 8963. DOI: http://dx.doi.org/10.5821/ace.14.42.8963

${ }^{1}$ Dr. Arquitecto. Profesor de la Escuela de Arquitectura, Universidad de las Américas, Chile (ORCID ID: $0000-$ 0002-1930-4691, Researcher ID: J-8557-2019, Scopus ID: 57200275694), ${ }^{2}$ Constructor Civil, M. Sc. Profesor y Director de la Escuela de Construcción Civil, Universidad de las Américas, Chile (ORCID ID: 0000-00017556-8352, Scopus ID: 57204744776) Correo de contacto: jvergara@udla.cl 


\title{
Urban capital gain recovery simulation for Line 3 of the Santiago Metro
}

Abstract

\begin{abstract}
This article corresponds to a simulation of capital gains recovery applied to the transactions of land and new departments for 40 cases located near the new line 3 of Metro de Santiago. In Chile, the recovery of capital gains does not exist as a public policy, although different actors have set up the debate to evaluate their implementation before various announcements about new metro lines in the Metropolitan Region of Santiago. The main reason for this article is to contribute to the debate with empirical data on the potential consequences of applying these instruments to subway lines, taking as a reference the models of recovery of surplus value in Colombia. With this simulation, the study tests Martim Smolka's proposals for recovery of capital gains in Latin American nations in order to improve the provision of fiscal funds and improve urban environments. In Chile, this exercise has not yet been carried out, although there are similar contributions that, from different approaches, value the results that arise from this study. The methodology is quantitative, exploratory and inductive in nature, using the profitability measurement by NPV based on a historical survey of the project, its values, the price of land and its typologies, to apply a 50\% value capture to the profits of land and $30 \%$ of the departments. The findings show a good possibility of collection but that requires specific adjustments so that these instruments do not prevent the housing market from becoming insolvent.
\end{abstract}

Keywords: Public investment; inequality; Chile; urban economy; real estate profitability

\section{Introducción}

En Chile, la vivienda es un bien sujeto a un mercado de baja regulación, organizada por los agentes del mercado y subsidiada por el Estado para los hogares de menores ingresos (Garreton, 2017) en una estrategia que se ha caracterizado como una política de bienestar neoliberal (Alvarado-Peterson, 2019). A pesar de los esfuerzos desde las políticas públicas, existe contundente evidencia de que el subsidio a la demanda para proyectos de vivienda de escasos recursos ha terminado por aumentar el precio contribuyendo a su inflación (Razmilic, 2010). Esto también ocurre para los subsidios de renovación urbana, originalmente destinados a la clase media, donde el subsidio es capturado por la empresa que vende las unidades de vivienda, sin con ello beneficiar directamente a los compradores (López-Morales, 2016). Considerando los altos niveles de segregación en ciudades como Santiago, el Estado ha comenzado a invertir en infraestructuras de transporte que mejoren la movilidad interna de la ciudad y reduzcan distancias entre comunas con buen acceso a bienes públicos y aquella con importante déficit. Bajo esta premisa, diversas líneas de metro se han anunciado por parte de la autoridad central. Metro, es el sistema de transporte público Santiaguino conformado por trenes subterráneos en su mayoría. Los recientes anuncios de expansión de líneas de metro han detonado un importante desarrollo inmobiliario en torno a nuevas líneas. A pesar de la inversión en infraestructura de movilidad urbana, la segregación persiste a causa de los altos precios de la vivienda.

ACE, 14 (42) CC BY-ND 3.0 ES | UPC Barcelona, España | Simulación de recuperación de plusvalía urbana para Línea 3 del Metro de Santiago. DOI: http://dx.doi.org/10.5821/ace.14.42.8963 
Desde el año 2008, el Índice Real del Precio de la Vivienda ha subido en un 70.96\% mientras las remuneraciones de los trabajadores solo han aumentado en un 20.43\% (Figura 1). Esta complejidad se suma al difícil panorama a nivel nacional, donde la demanda estructural de vivienda es de 497,560 unidades, muy similar al déficit de 1998 cuantificado en 497,012 unidades (Fundación Vivienda, 2019). Todo esto a pesar que desde el año 1998 hasta diciembre de 2018 se han construido 2,805,069 unidades de viviendas nuevas (Instituto Nacional de Estadísticas, 2019).

Figura 1. Índice real del precio de la vivienda en Chile contra el índice de remuneraciones globales

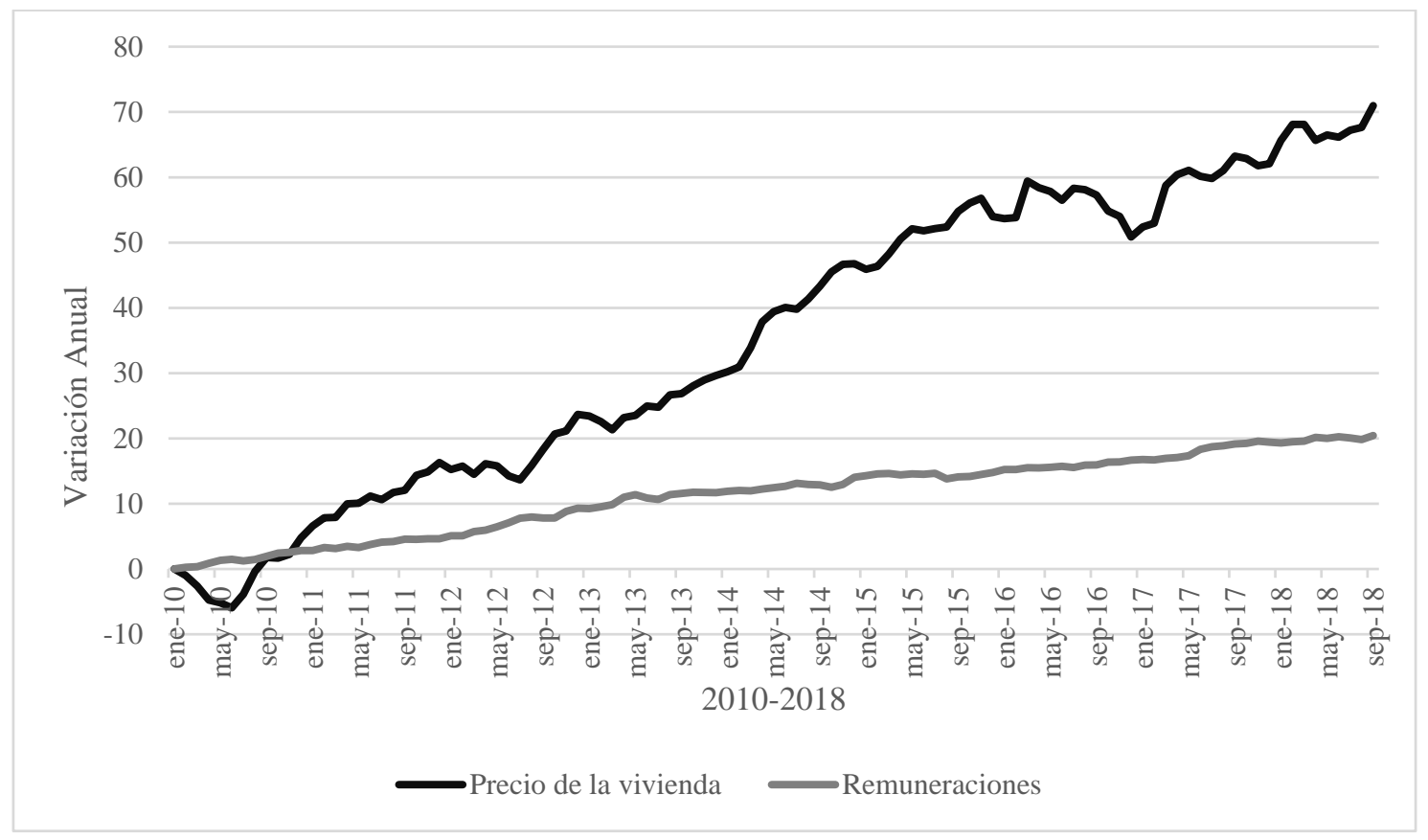

Fuente: Banco Central de Chile (2018).

Según reporte de la OECD de 2013, las ciudades chilenas se encontraban entre las más segregadas a nivel de los países miembros de esta organización de cooperación internacional, situación particularmente compleja en la ciudad de Santiago (OECD Urban Policy Reviews, Chile 2013, 2013). En este contexto de segregación, las inversiones y mejoramientos de barrios podrían estar causando procesos de desplazamiento o gentrificación de residentes ante desiguales capacidades de compra contra un desarrollo inmobiliario focalizado en sectores consolidados de la ciudad (Sabatini, Rasse, Cáceres, Robles y Trebilcock, 2017). Estos desplazamientos, incluso, se podrían estar generando con la participación del Estado mediante subsidios de localización (Inzulza y Cárdenas, 2017).

La concentración de los desarrolladores inmobiliarios en zonas consolidadas, en un modelo de desarrollo urbano basado en las reglas del mercado sin fuertes regulaciones, sería parte de las causas de la segregación residencial que experimenta la ciudad de Santiago (Link, Valenzuela y Fuentes, 2015), que propende a que el suelo se transforme en un nicho de renta de alta utilidad para el capital financiero (Hidalgo et al. 2016. "Aguas de ficción a la carta: la producción de naturaleza como nicho de renta. Bienes comunes y espacio urbano exclusivo en torno a las crystal lagoons”. En: Alvarado, Gómez e Hidalgo, 2016). Una revisión de este problema se puede ver al revisar la disparidad en la distribución de los hogares de mayores y menores ingresos, como se puede ver en la Tabla 1.

ACE, 14 (42) CC BY-ND 3.0 ES | UPC Barcelona, España | Simulación de recuperación de plusvalía urbana para Línea 3 del Metro de Santiago. DOI: http://dx.doi.org/10.5821/ace.14.42.8963 
Tabla 1. Composición de comunas según decil de ingresos

\begin{tabular}{|c|c|c|c|c|c|c|c|c|c|c|}
\hline \multirow{2}{*}{ Comuna } & \multicolumn{10}{|c|}{ Composición de comunas según decil de ingresos } \\
\hline & I & II & III & IV & V & VI & VII & VIII & IX & $\mathrm{x}$ \\
\hline Vitacura & $0,5 \%$ & - & $0,2 \%$ & - & $2,5 \%$ & $2,6 \%$ & $5,0 \%$ & $10,8 \%$ & $24,9 \%$ & $53,6 \%$ \\
\hline Providencia & $1,1 \%$ & $1,0 \%$ & $1,4 \%$ & $2,1 \%$ & $2,8 \%$ & $3,8 \%$ & $6,0 \%$ & $9,4 \%$ & $24,2 \%$ & $48,3 \%$ \\
\hline Las Condes & $1,9 \%$ & $2,8 \%$ & $2,0 \%$ & $2,0 \%$ & $5,1 \%$ & $3,9 \%$ & $5,6 \%$ & $9,1 \%$ & $24,0 \%$ & $43,7 \%$ \\
\hline La Reina & $1,4 \%$ & $2,9 \%$ & $8,4 \%$ & $3,4 \%$ & $8,3 \%$ & $6,4 \%$ & $6,2 \%$ & $10,4 \%$ & $25,3 \%$ & $27,5 \%$ \\
\hline Ñuñoa & $3,1 \%$ & $3,7 \%$ & $3,2 \%$ & $3,7 \%$ & $6,3 \%$ & $4,5 \%$ & $8,8 \%$ & $15,0 \%$ & $24,5 \%$ & $27,3 \%$ \\
\hline Lo Barnechea & $9,4 \%$ & $10,1 \%$ & $10,6 \%$ & $8,1 \%$ & $7,6 \%$ & $12,3 \%$ & $7,0 \%$ & $9,3 \%$ & $7,6 \%$ & $18,1 \%$ \\
\hline Santiago & $3,5 \%$ & $3,8 \%$ & $4,6 \%$ & $7,1 \%$ & $11,3 \%$ & $8,3 \%$ & $13,9 \%$ & $15,9 \%$ & $17,8 \%$ & $13,8 \%$ \\
\hline Peñalolén & $10,2 \%$ & $12,8 \%$ & $12,2 \%$ & $11,2 \%$ & $11,1 \%$ & $8,7 \%$ & $6,9 \%$ & $8,9 \%$ & $8,7 \%$ & $9,3 \%$ \\
\hline San Miguel & $7,7 \%$ & $10,4 \%$ & $6,1 \%$ & $10,1 \%$ & $11,8 \%$ & $10,5 \%$ & $10,1 \%$ & $13,7 \%$ & $11,5 \%$ & $8,1 \%$ \\
\hline Colina & $17,8 \%$ & $14,7 \%$ & $13,7 \%$ & $11,9 \%$ & $15,0 \%$ & $5,7 \%$ & $6,0 \%$ & $3,1 \%$ & $4,2 \%$ & $8,0 \%$ \\
\hline La Cisterna & $12,8 \%$ & $13,6 \%$ & $13,6 \%$ & $7,1 \%$ & $9,5 \%$ & $11,5 \%$ & $7,7 \%$ & $7,8 \%$ & $11,7 \%$ & $4,5 \%$ \\
\hline Recoleta & $11,5 \%$ & $12,0 \%$ & $12,5 \%$ & $13,1 \%$ & $13,0 \%$ & $11,4 \%$ & $8,3 \%$ & $9,4 \%$ & $4,5 \%$ & $4,4 \%$ \\
\hline Macul & $9,3 \%$ & $9,2 \%$ & $13,2 \%$ & $11,4 \%$ & $13,1 \%$ & $12,3 \%$ & $8,2 \%$ & $15,3 \%$ & $5,3 \%$ & $2,8 \%$ \\
\hline La Florida & $10,0 \%$ & $12,3 \%$ & $9,3 \%$ & $10,0 \%$ & $12,7 \%$ & $10,0 \%$ & $8,4 \%$ & $13,9 \%$ & $10,7 \%$ & $2,7 \%$ \\
\hline Maipú & $8,2 \%$ & $8,8 \%$ & $13,8 \%$ & $10,4 \%$ & $14,6 \%$ & $13,3 \%$ & $10,0 \%$ & $10,1 \%$ & $8,6 \%$ & $2,3 \%$ \\
\hline Quilicura & $8,3 \%$ & $11,5 \%$ & $15,2 \%$ & $15,2 \%$ & $10,2 \%$ & $13,8 \%$ & $9,5 \%$ & $9,6 \%$ & $4,9 \%$ & $2,0 \%$ \\
\hline Cerrillos & $17,0 \%$ & $11,7 \%$ & $16,7 \%$ & $19,5 \%$ & $10,3 \%$ & $9,2 \%$ & $2,6 \%$ & $6,9 \%$ & $4,3 \%$ & $1,9 \%$ \\
\hline Estación Central & $15,0 \%$ & $15,6 \%$ & $12,0 \%$ & $10,7 \%$ & $9,1 \%$ & $16,5 \%$ & $7,1 \%$ & $7,3 \%$ & $5,1 \%$ & $1,6 \%$ \\
\hline Renca & $5,3 \%$ & $20,1 \%$ & $18,1 \%$ & $9,5 \%$ & $15,9 \%$ & $12,3 \%$ & $7,8 \%$ & $7,0 \%$ & $2,5 \%$ & $1,5 \%$ \\
\hline Independencia & $8,1 \%$ & $6,1 \%$ & $11,7 \%$ & $14,3 \%$ & $9,2 \%$ & $19,7 \%$ & $12,0 \%$ & $11,2 \%$ & $6,3 \%$ & $1,4 \%$ \\
\hline Pedro Aguirre Cerda & $14,8 \%$ & $11,8 \%$ & $16,2 \%$ & $13,6 \%$ & $12,7 \%$ & $12,7 \%$ & $8,2 \%$ & $5,5 \%$ & $3,3 \%$ & $1,2 \%$ \\
\hline El Bosque & $14,4 \%$ & $20,8 \%$ & $15,3 \%$ & $8,6 \%$ & $14,4 \%$ & $5,3 \%$ & $9,8 \%$ & $5,5 \%$ & $4,9 \%$ & $0,9 \%$ \\
\hline Puente Alto & $11,7 \%$ & $12,5 \%$ & $12,9 \%$ & $13,0 \%$ & $11,6 \%$ & $10,8 \%$ & $13,3 \%$ & $7,3 \%$ & $6,1 \%$ & $0,8 \%$ \\
\hline Quinta Normal & $9,2 \%$ & $13,5 \%$ & $10,7 \%$ & $18,6 \%$ & $10,5 \%$ & $11,6 \%$ & $16,4 \%$ & $4,9 \%$ & $4,0 \%$ & $0,7 \%$ \\
\hline Pudahuel & $12,3 \%$ & $17,9 \%$ & $7,7 \%$ & $13,9 \%$ & $10,8 \%$ & $15,1 \%$ & $11,3 \%$ & $7,4 \%$ & $2,9 \%$ & $0,7 \%$ \\
\hline Lo Prado & $10,3 \%$ & $14,0 \%$ & $14,3 \%$ & $15,4 \%$ & $12,5 \%$ & $12,5 \%$ & $12,3 \%$ & $5,9 \%$ & $2,0 \%$ & $0,6 \%$ \\
\hline Huechuraba & $17,2 \%$ & $13,4 \%$ & $13,4 \%$ & $13,9 \%$ & $8,2 \%$ & $13,0 \%$ & $10,8 \%$ & $8,6 \%$ & $1,0 \%$ & $0,6 \%$ \\
\hline Cerro Navia & $21,1 \%$ & $19,2 \%$ & $7,2 \%$ & $14,3 \%$ & $13,5 \%$ & $11,7 \%$ & $8,0 \%$ & $2,5 \%$ & $2,0 \%$ & $0,5 \%$ \\
\hline Lo Espejo & $15,7 \%$ & $22,2 \%$ & $12,8 \%$ & $12,4 \%$ & $16,1 \%$ & $8,3 \%$ & $5,5 \%$ & $3,5 \%$ & $3,0 \%$ & $0,4 \%$ \\
\hline Conchalí & $11,1 \%$ & $13,7 \%$ & $20,5 \%$ & $12,5 \%$ & $8,1 \%$ & $11,0 \%$ & $10,4 \%$ & $10,4 \%$ & $2,1 \%$ & $0,3 \%$ \\
\hline San Joaquín & $8,1 \%$ & $14,6 \%$ & $12,0 \%$ & $19,0 \%$ & $12,1 \%$ & $14,1 \%$ & $9,8 \%$ & $7,4 \%$ & $2,7 \%$ & $0,2 \%$ \\
\hline La Granja & $11,9 \%$ & $20,3 \%$ & $14,2 \%$ & $10,6 \%$ & $14,2 \%$ & $14,2 \%$ & $8,7 \%$ & $4,7 \%$ & $1,1 \%$ & $0,1 \%$ \\
\hline La Pintana & $23,3 \%$ & $17,2 \%$ & $17,4 \%$ & $13,6 \%$ & $11,3 \%$ & $8,7 \%$ & $6,3 \%$ & $1,6 \%$ & $0,4 \%$ & $0,1 \%$ \\
\hline San Ramón & $17,2 \%$ & $18,5 \%$ & $11,5 \%$ & $19,0 \%$ & $11,5 \%$ & $6,0 \%$ & $8,4 \%$ & $5,1 \%$ & $3,0 \%$ & - \\
\hline
\end{tabular}

Fuente: Elaboración propia en base a Encuesta CASEN 2017. Nota: La tabla indica el porcentaje de hogares según decil de ingreso socioeconómico para cada comuna presentada. Las comunas donde hay mayor concentración de menores ingresos en el decil I, se han marcado con negrita, lo mismo para las de mayores ingresos en el decil X. Con excepción de la comuna de Colina y Peñalolén, en pocas comunas se logran ver distribuciones similares de grupos de altos y bajos ingresos. 
Figura 1. Mapa comparado de comunas según concentración de población del 10\% de menores ingresos(izquierda) con población del 10\% de altos ingresos (derecha)

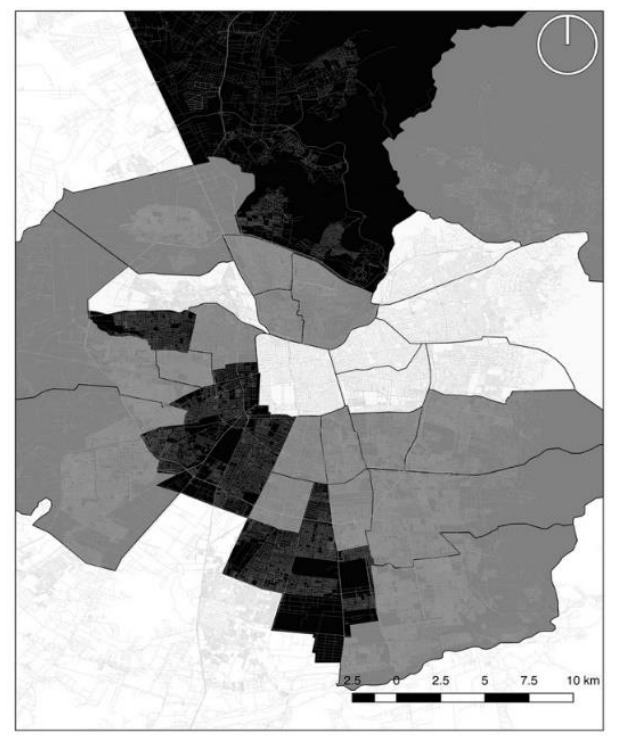

Leyenda

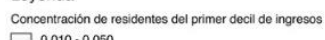

$\square \quad 0.010 \cdot 0.050$

$0.050 \cdot 0.130$
$0.130 \cdot 0.230$

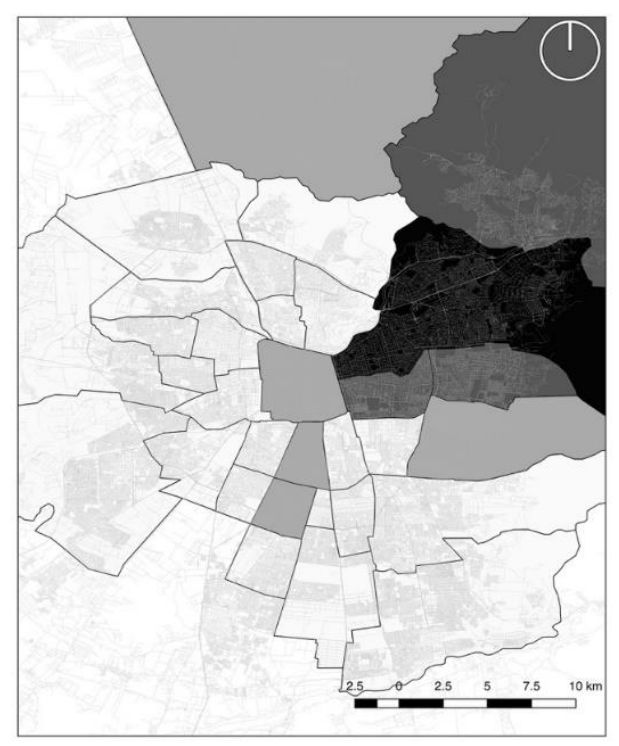

Leyenda

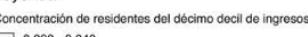

马 $0.000 \cdot 0.040$

每 $0.040 \cdot 0.140$

Fuente: elaboración propia en base a encuesta CASEN 2017.

Esta diferenciación en los ingresos de los hogares se traduce en comunas para ricos y pobres (Valenzuela, Pressacco, Cienfuegos y Penaglia, 2015), lo que repercute en el sistema de ordenamiento interno comunal dado que cada comuna debe autofinanciarse (Vergara-Perucich, 2018) y, como es de esperarse, las comunas con residentes de altos ingresos generan más consumo, más aporte a las arcas municipales y mayor regularidad de pago de impuestos. Sabiendo de la existencia de comunas de buena calidad en materia de gestión de los asuntos referidos a los espacios públicos y otras de baja calidad urbana, el Estado ha optado por una estrategia de fuerte inversión en transporte público que permita reducir los tiempos de viaje entre comunas con buena provisión de bienes públicos y las de bajos niveles de bienes públicos. Al respecto, el presidente Sebastián Piñera hizo el anuncio en su cuenta anual del año 2019: "Pero además de ciudades más integradas y amigables nos estamos haciendo cargo de una verdadera revolución en materia de transporte público, a través del Proyecto Transporte Tercer Milenio. Esta modernización incluye la duplicación de la red del Metro en la Región Metropolitana, pasando de 150 a 300 km, a través de la recientemente inaugurada Línea 3, pero también de las nuevas Líneas 7, 8, 9 y 10, y las extensiones de la Línea 2 hasta San Bernardo, la 3 a Quilicura, la 4 a Bajos de Mena y la 6 a Isidora Goyenechea, y está en pleno estudio un tren que permitirá unir la capital con el aeropuerto Arturo Merino Benítez. Todo esto va a permitir que la mitad de los habitantes de Santiago puedan caminar desde su hogar al Metro o desde su lugar de trabajo al Metro." 1

Metro es una empresa público-privada cuyo directorio depende del nombramiento de la Corporación del Fomento de la Producción (CORFO) y del Ministerio de Hacienda, según la Ley 18772 que transforma a Metro en Sociedad Anónima controlada por el Estado como socio accionario

1 Discurso anual del presidente de la república rindiendo cuentas ante la ciudadanía. Disponible en: https://prensa.presidencia.cl/comunicado.aspx?id=96555 
mayoritario, que es fiscalizada por la Superintendencia de Valores y Seguros, que emite acciones ordinarias Serie A y B para su capitalización. El anuncio del presidente Piñera, se ha acompañado de una importante difusión por parte de diferentes actores cercanos al gobierno, valorando en aporte que esta infraestructura tendrá sobre el bienestar de la población beneficiada. El actual presidente de Metro. Louis de Grange, plantea que Metro siempre ha sido el eje estructural del transporte urbano que permite cambiar la vida de las personas (de Grange, 2018). De forma similar, en la inauguración de la extensión de la línea 2 de Metro, la Ministra de Transportes y Telecomunicaciones para el período 2018-2022, Gloria Hutt, decía que "El transporte público avanza a paso firme para continuar mejorando la calidad de vida de todos sus usuarios. Hoy iniciamos los trabajos de extensión de la Línea 2, lo que para muchos era un sueño, especialmente en las comunas de El Bosque y San Bernardo, las que por primera vez se sumarán a la red de Metro. Sus habitantes disfrutarán de una mayor conectividad y con alto estándar" (Hutt, 2019). Sin duda, la extensión de líneas de metro en la ciudad de Santiago es una buena noticia para los beneficiarios, sin embargo, también existen ganancias económicas que se benefician de esta extensión de líneas sin realizar inversiones y que en otros lugares son sujetos de regulación. Sin embargo, este efecto de aumento de valor, contiene en si una dualidad de intereses y de facultades sobre el bien público y el privado (Alegret y Cabre i Puig, 2011).

Al respecto, el mecanismo de recuperación de plusvalía para inversiones públicas similares a Metro se ha implementado en otros lugares de América Latina, con positivos resultados (M. Smolka y Furtado, 2001). Quizás el caso colombiano sea el más llamativo, debido a que ya lleva funcionando muchos años y existe documentación que clarifica sus efectos y desmitifica potenciales restricciones al desarrollo urbano (Garza, 2019). Por otro lado, su aplicación es clara y regulada por una ley que surge luego de años de deliberación (desde 1921) para diseñar un modelo apropiado de captación en los mecanismos de contribución de valorización (Smolka, 2013; Vejarano, 2008).

Un experto en estos mecanismos de gestión urbana para América Latina es Martim Smolka, quien ha recomendado realizar exploraciones sobre estos instrumentos en naciones que aún no las implementan, como es el caso Chileno (M. Smolka, 2013). A este llamado, diversos expertos a nivel nacional buscan que se instale este debate. Al respecto, Smolka propone que este debate vaya más allá de las 4 I que obstaculizan la búsqueda de soluciones al desarrollo de ciudades más equitativas: interés creado por parte de desarrolladores y tenedores de portafolios de terrenos, ideología que rechaza la intervención pública en el mercado, ignorancia que intenta relacionar la inflación por regulación que afectaría los precios de la vivienda y la inercia en estados culturalmente predispuestos a subsidiar soluciones de integración social (Smolka, 2013).

El debate académico en Chile sobre estos mecanismos tiene vertientes diversas. Por un lado, urbanistas como Pablo Allard plantean que, para el caso particular de Metro, la captura de plusvalía no sería la herramienta idónea sino que sería mejor ampliar las facultades de Metro para desarrollar otro tipo de iniciativas que mejoren el espacio urbano (Allard y Cociña, 2018). El urbanista Ivan Poduje ha catalogado el modelo de captura de plusvalía como un fetiche idealizado para resolver problemas urbanísticos que son mucho más complejos (Poduje, 2019). Ciertamente, como plantea Camila Cociña, la solución urbanística para problemas complejos como la segregación no es una sola y se necesitará aproximaciones heterogéneas (Allard y Cociña, 2018). De momento, simulaciones y aproximaciones a la posibilidad de desarrollar capturas de plusvalía urbana en Chile son escasas.

Uno de los pocos ejemplos de simulación fue desarrollado por Ernesto Lopez, Claudia Sanhueza, Sebastián Espinoza y Felipe Órdenes, quienes presentan evidencia que indicaría que la inversión estatal sobre líneas de metro aumenta en un 25.6\% las ganancias de las empresas inmobiliarias y en un $5.5 \%$ para los propietarios de los suelos, ante lo cual proponen avanzar hacia un impuesto a la renta de suelo, similar al modelo de recuperación de plusvalías (López-Morales, Sanhueza, Espinoza y Órdenes, 2019).

ACE, 14 (42) CC BY-ND 3.0 ES | UPC Barcelona, España | Simulación de recuperación de plusvalía urbana para Línea 3 del Metro de Santiago. DOI: http://dx.doi.org/10.5821/ace.14.42.8963 
Figura 2. Esquema descriptivo del estudio

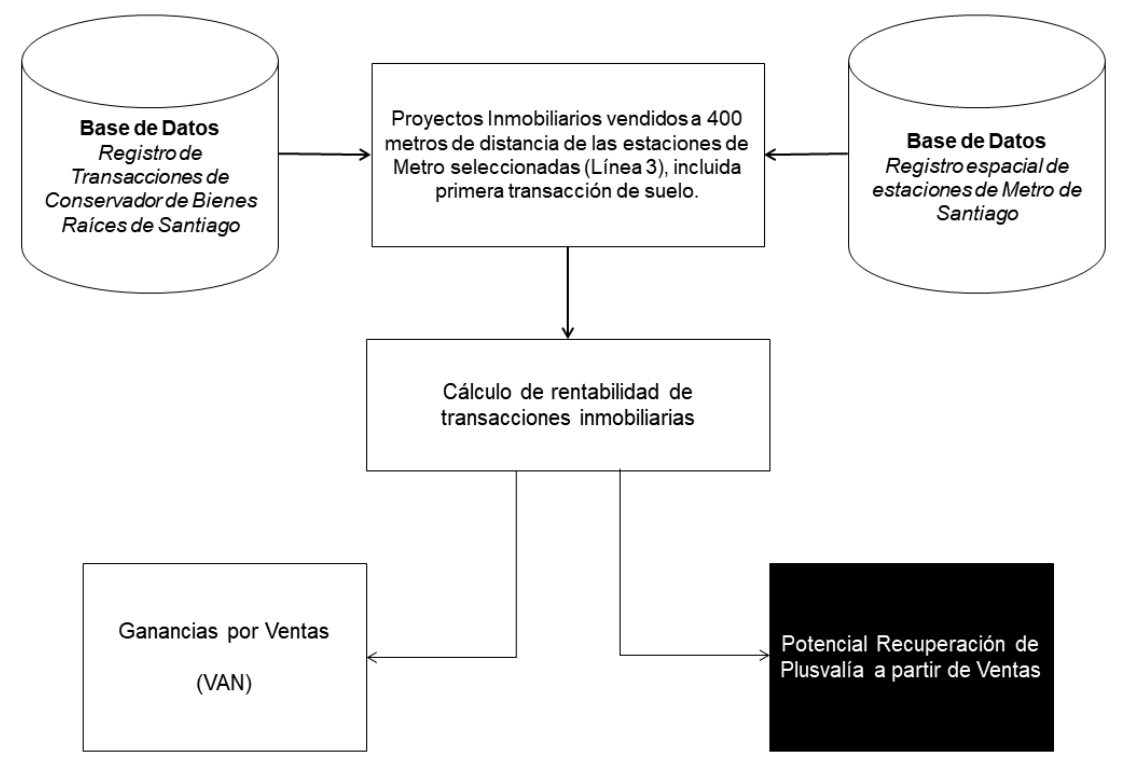

Fuente: Elaboración de los autores.

Para contribuir en este debate, en este artículo, desarrollamos un estudio exploratorio sobre el precio de la vivienda en la ciudad de Santiago de Chile, con especial énfasis en la recientemente inaugurada línea 3 del metro. El objetivo es, en primera instancia, conocer las ganancias presuntas de estos proyectos de vivienda en altura, medidos por el Valor Actual Neto. Luego, se planta un supuesto: el anuncio de nuevas estaciones de metro produce un aumento significativo del valor d suelo y de las viviendas que se comercializan en el sector aledaño. Para testear este supuesto, se hace una revisión histórica de los datos de cada estación (400 metros de radio), en busca de conocer el valor de suelo antes del anuncio de las estaciones de la nueva línea 3 (año 2010) y los valores de las viviendas y el suelo, una vez inaugurada la línea (año 2019). De esta manera (Figura 2), se podrán determinar los presuntos aumentos por nuevas líneas y aplicar una recuperación de plusvalía. En el presente estudio, entonces, se revisará cuanto podría recaudar el estado con la inauguración de la nueva línea 3 del metro y cuanto afecta esto la rentabilidad del mercado inmobiliario, medido por el Valor Actual Neto (VAN). Para muchos de los datos presentados, se utiliza la Unidad de Fomento (UF), que en Chile se usa como una medida de valor de cambio indexado por el Índice de Precios del Consumidor con el objetivo de que su reajuste se realice automáticamente en coherencia con las variaciones económicas nacionales. Para facilitar la lectura, hemos agregado también la transformación en Euros de octubre 2019.

Esta es una investigación de carácter inductiva, exploratoria y cuantitativa, que trabaja con datos obtenidos desde archivos oficiales unificados para el estudio específico de un conjunto de proyectos de diversa tipología ubicados en la comuna de Santiago Centro, correspondiente al CBD local. Luego de presentar la metodología a utilizar, se desarrolla un análisis sistemático sobre 40 proyectos sobre la estructura de precios de proyectos de vivienda en altura ubicados en torno a la línea 3 del Metro, para determinar cuáles son sus rentabilidades esperadas a la hora de elaborar las propuestas. A modo de anticipación de los resultados obtenidos en el estudio, la captura de plusvalía directa sobre ventas de suelos y departamentos de los 40 proyectos evaluados, podría alcanzar para adquirir más de 4000 unidades de vivienda pública o para financiar gran parte del costo de inversión de la misma Linea 3 de Metro. El impacto sobre la rentabilidad del negocio inmobiliario es variable, pero en el 82.5\% de los casos mantienen importantes niveles de ingresos medidos por VAN.

ACE, 14 (42) CC BY-ND 3.0 ES | UPC Barcelona, España | Simulación de recuperación de plusvalía urbana para Línea 3 del

Metro de Santiago. DOI: http://dx.doi.org/10.5821/ace.14.42.8963 


\section{Métodos}

El método busca reconstruir el historial de proyectos de vivienda nuevos ubicados en el área cercana a las nuevas estaciones de la Línea 3 del Metro (Figura 3), considerando un radio máximo de 400 metros. Se han contemplado únicamente los proyectos disponibles en el año 2019, cuando dicha línea entró en funcionamiento. A partir de los datos del Conservador de Bienes Raíces de Santiago, los expedientes municipales de cada proyecto y de la ficha de márquetin de cada proyecto, se ha reconstruido su rentabilidad de ventas, los valores de los terrenos comercializados para la ejecución de los proyectos y los resultados de ventas. Para la reconstrucción de los proyectos, se utilizó principalmente la base de datos facilitada por la plataforma InCiti.com, que acelera la búsqueda de datos por dirección específica, para el área metropolitana de Santiago.

Figura 3. Línea 3 del Metro de Santiago

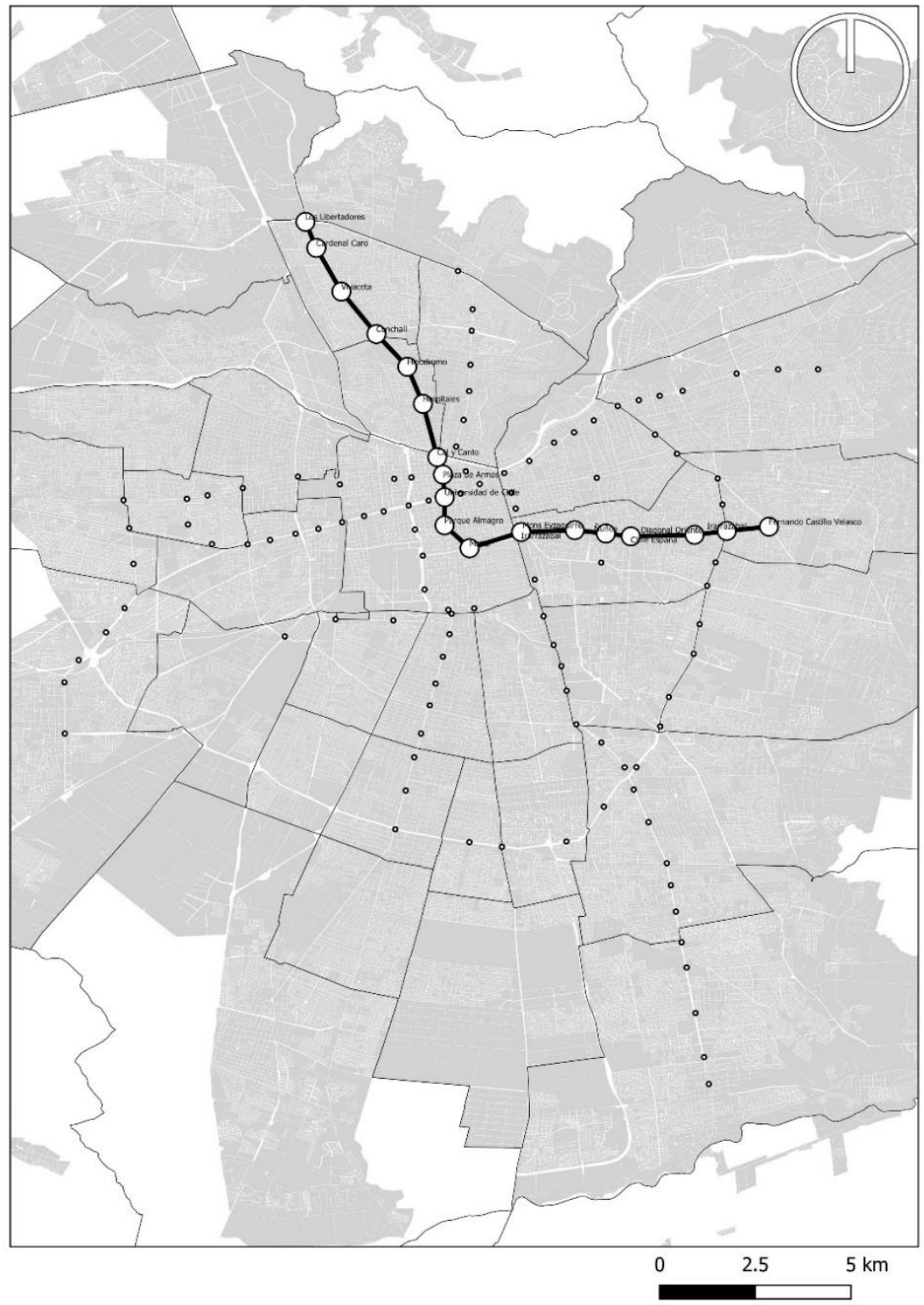

Fuente: Elaboración propia en base a datos de Metro de Santiago S.A.

ACE, 14 (42) CC BY-ND 3.0 ES | UPC Barcelona, España | Simulación de recuperación de plusvalía urbana para Línea 3 del

Metro de Santiago. DOI: http://dx.doi.org/10.5821/ace.14.42.8963 
El modelo de costos de construcción se basa en una estimación presupuesto asociado al nivel de terminaciones, equivalente al modelo de validación de costos de reposición del Servicio de Impuestos Internos (SII) de Chile. Además, se estableció una configuración rítmica de avance de obra (Tabla 2), que trasforma el presupuesto total de construcción en un flujo acorde a un avance ideal de obra, característico de la edificación en altura, basado en un modelo de curva $S$ de planificación de proyectos de construcción (Miskawi, 1989), donde la mayor parte de la inversión se encuentra hacia la mitad temporal del proyecto. Considerando las velocidades constructivas en Chile, se considera que la construcción del edificio dependerá de la cantidad de pisos, avanzando 1 piso por cada mes de avance. El resto del flujo se calcula a partir de la velocidad de venta del proyecto. Es importante mencionar que la velocidad de venta del proyecto también ha sido elaborada en base a datos de cada proyecto. Finalmente, sobre estos flujos se realizan los cálculos de rentabilidad de cada obra analizada.

Tabla 2. Modelo de análisis de flujos de caja

\begin{tabular}{|c|c|c|c|c|c|c|c|c|c|c|c|c|c|c|c|c|c|c|c|c|}
\hline Flujo & Cero & $\begin{array}{l}\text { Venta en } \\
\text { Verde } \\
\text { (Antes de } \\
\text { terminar) }\end{array}$ & & & & & Recepción & & & $\begin{array}{l}\text { Venta en Gris } \\
\text { (obra acabada y } \\
\text { recepcionada) }\end{array}$ & & & & & & & & & & Total \\
\hline Tiempos & 0 & 1 & 2 & 3 & ... & j & $j+1$ & $\ldots$ & $j+3$ & $j+4$ & ... & $\ldots$ & $\ldots$ & $\ldots$ & $\ldots$ & $\ldots$ & $\ldots$ & $\ldots$ & $n$ & \\
\hline $\begin{array}{l}\text { Unidades } \\
\text { Vendidas }\end{array}$ & - & - & - & - & - & - & - & - & - & - & - & - & - & - & - & - & - & - & - & \\
\hline Ingresos & - & - & - & - & - & - & - & - & - & - & - & - & - & - & - & - & - & - & - & \\
\hline $\begin{array}{l}\text { Ingresos por } \\
\text { PIE }\end{array}$ & - & - & - & - & - & - & - & - & - & - & - & - & - & - & - & - & - & - & - & \\
\hline $\begin{array}{l}\text { Ingresos por } \\
\text { Créditos } \\
\text { Hipotecarios }\end{array}$ & - & - & - & - & - & - & - & - & - & - & - & - & - & - & - & - & - & - & - & \\
\hline $\begin{array}{l}\text { Costo del } \\
\text { Terreno }\end{array}$ & - & - & - & - & - & - & - & - & - & - & - & - & - & - & - & - & - & - & - & \\
\hline $\begin{array}{l}\text { Costos de } \\
\text { Construcción }\end{array}$ & - & - & - & - & - & - & - & - & - & - & - & - & - & - & - & - & - & - & - & \\
\hline $\begin{array}{l}\text { Costos de } \\
\text { Asesorías }\end{array}$ & - & - & - & - & - & - & - & - & - & - & - & - & - & - & - & - & - & - & - & \\
\hline $\begin{array}{l}\text { Costos de } \\
\text { Permisos }\end{array}$ & - & - & - & - & - & - & - & - & - & - & - & - & - & - & - & - & - & - & - & \\
\hline $\begin{array}{l}\text { Costos de } \\
\text { Márketing }\end{array}$ & - & - & - & - & - & - & - & - & - & - & - & - & - & - & - & - & - & - & - & \\
\hline Flujo de Caja & & & & & & & & & & & & & & & & & & & & _ \\
\hline
\end{tabular}

Fuente: Elaboración de los autores.

El modelo de ingresos consiste determinar un inicio, termino y ritmo de ventas en un periodo determinado. Como supuesto se consideró la velocidad de venta declarada en la base de datos de la plataforma InCiti y contrastada con los datos declarados por la Cámara Chilena de la Construcción. Se usó un supuesto que dice que las ventas mensuales se desarrollan de forma constante en base a la tasa de ventas registrada hasta agotar el stock de viviendas disponibles. Esto implica que, en un escenario negativo, la velocidad de venta de los proyectos es de 3 años. Con estos datos, se calcula el Valor Actual Neto (VAN) para tener una referencia basal de la rentabilidad actual de proyectos inmobiliarios en sectores donde ha existido inversión pública.

ACE, 14 (42) CC BY-ND 3.0 ES | UPC Barcelona, España | Simulación de recuperación de plusvalía urbana para Línea 3 del

Metro de Santiago. DOI: http://dx.doi.org/10.5821/ace.14.42.8963 
El modelo de evaluación financiera, se realizó mediante un ejercicio de construcción de flujo de caja considerando el periodo inicial, el valor de la compra del terreno, los gastos en proyectos y permisos. Por periodos mensuales, se calcula el flujo de ingresos y egresos, para después calcular el VAN.

Es importante mencionar que el mercado de la vivienda en Chile no funciona en base a datos transparentes. Por un lado, los precios de la vivienda solo son registrados en archivos impresos en papel (no en digital) que se almacenan en los conservadores de bienes raíces dependiendo de cada territorio, en este caso, en el de Santiago. Por otro lado, los montos de inversión en construcción no son registrados de forma pública por todas las empresas y esto es únicamente obligatorio para aquellos proyectos de gran envergadura, lo que se incorpora en el Sistema de Evaluación Ambiental a la hora de ingresar proyectos para ser evaluados y aprobados. Dicha información, es provista por la misma empresa. Otra limitante es que la tasación fiscal de inmuebles está completamente distanciada de la tasación comercial de los mismos. Esto quiere decir que, entre otras cosas, las transacciones de inmuebles pagan impuestos contra la tasación fiscal por lo que no necesariamente el Servicio de Impuestos Internos maneja información de los costos comerciales de las obras edificadas. Esto ha determinado que se tomen algunas decisiones metodológicas sobre cómo enfrentar la evaluación de cada proyecto.

Para la obtención de los datos y así completar la tabla de proyectos, se ha recurrido a las siguientes fuentes:

1. Conservador de Bienes Raíces de Santiago, entidad pública que registra las transacciones de propiedades en la ciudad, indicando datos personales de quienes realizan las transacciones, valores, dimensiones y características generales de cada propiedad. Esta información fue obtenida a partir de datos recabados por InCiti.

2. Velocidad de venta de las propiedades para determinar sus tiempos de construcción, fueron elaborados en base a datos de la Cámara Chilena de la Construcción y a los antecedentes de avances de proyectos recabados por InCiti.

3. Para la estimación de costos de construcción, hemos desarrollado un cálculo en base a datos obtenidos desde el catálogo de actividades de la construcción ONDAC y de las tablas estimativas desarrolladas por el Servicio de Impuestos Internos y el Ministerio de Vivienda y Urbanismo. Dependiendo del volumen construido, hemos utilizado un valor de construcción de UF/m2 estimado en 22,5 a 25 para construcción sobre nivel 0; y de 17 UF/m2 para construcción de subterráneos. Estos valores son netos.

4. Para estimar los ingresos de los proyectos por ventas, se ha utilizado el valor comercial anunciado en sitios web especializados (portalinmobiliario.com y toctoc.com), contrastándolo con la información de transacciones indicados en las bases de datos de InCiti y en los propios anuncios de las empresas que comercializaban sus obras.

5. A los costos de inversión final se han agregado los gastos correspondientes a publicidad y ventas, asesorías y diseño del proyecto, siguiendo el modelo de Julio Aznares (Aznares en Simian y Niklitschek, 2017), ampliamente validado por la industria inmobiliaria en Chile.

Es importante mencionar que, en Chile, para transacciones inmobiliarias, se usa la Unidad de Fomento (UF), la cual es una medida de valor reajustable diariamente por el IPC, lo que permite que el valor de los inmuebles sea comparable entre dos diferentes períodos, algo muy útil para este ejercicio en particular. Aun así, se han indicado valores en Euro para facilitar la lectura del artículo. En ningún caso, este estudio desarrolla una evaluación por precios hedónicos, dado que hemos tenido acceso directo a los precios reales de transacciones durante toda la historia del proyecto, desde compra de suelo para desarrollo inmobiliario hasta la venta de la última vivienda comercializada. En ese sentido, no es el objeto de este trabajo establecer el impacto estadístico de la distancia a las estaciones de Metro sobre el precio final, sino evaluar cuanto valor se podría extraer para inversión pública desde la propia comercialización de los bienes raíces estudiados.

ACE, 14 (42) CC BY-ND 3.0 ES | UPC Barcelona, España | Simulación de recuperación de plusvalía urbana para Línea 3 del 


\subsection{Reconstrucción de historia de proyectos evaluados}

Dado que el mercado de la vivienda en Chile se presenta sin transparencia total en la obtención de los datos, la reconstrucción de la historia de cada proyecto tuvo que seguir un detallado proceso que se ilustra a continuación con un caso de un edificio revisado para la comuna de Santiago Centro, cercano a la estación Parque Almagro de la Línea 3 (Edificio Nº13). Este es un edificio de 1 y 2 dormitorios, del que la empresa inmobiliaria proyecta ganancias generales por UF 1,532,000; equivalente a un $22 \%$ de las ganancias proyectadas para proyectos nuevos terminados. En nuestra evaluación estos montos se complementan con otras informaciones del proyecto contenidas en sus permisos de edificación y en las transacciones, lo que nos hizo corregir el monto de ventas en un 9,09\%. Estas ganancias son declaradas en la memoria anual de la empresa, en relación a sus proyecciones para el año 2019. Esta memoria se encuentra en la Superintendencia de Valores y Seguros de Chile. Teniendo estas expectativas de ganancias como referencia, se revisa el detalle del mismo proyecto, para lo cual se accede a sus antecedentes planimétricos, permisos de edificación, declaración de impacto ambiental y transacciones en el Conservador de Bienes Raíces de Santiago (CBRS). Como contexto general, el proyecto se rige por la normativa del Plan Regulador Comunal de Santiago Centro. Este proyecto obtuvo su permiso de edificación el día 18 de junio de 2018, adecuándose a las normas indicadas en el Certificado de Informes Previos 153.610 del año 2016 (Zona $B$ del PRC de Santiago). Para este proyecto, se contemplan 546 departamentos a vender, con un costo estimativo de 76 UF/m2 por cada uno. Es decir, un departamento de $35 \mathrm{~m} 2$ costaría UF 2660. En el Sistema de Evaluación Ambiental, la empresa declara que la inversión para ejecutar el proyecto es del orden de UF 694.374. A este monto, le hemos sumado el costo que tuvo el terreno para su construcción, dimensionado en 4.612 m2, inscrito en el registro del Servicio de Impuestos Internos, cuya tasación fiscal es de 54.139 UF y su valor de venta inscrito en el CBRS fue de UF 161.122.

El edificio tiene 6 diferentes tipologías de departamentos, en 12 pisos, enterando 22.604 m2 a la venta, más 273 estacionamientos y bodegas vendidos a UF 450 y UF 55 respectivamente. Según la velocidad de venta registrada en este proyecto, la venta de toda la obra se calcula en 25 meses. El costo de construcción aplicados es de 24 UF/m2 para construcción sobre superficie y 17 UF/m2 para construcción de subterráneos. No se contempla financiamiento bancario para la evaluación de este proyecto ni para ninguno de los evaluados. Entonces, con esta evidencia empírica, los cuales pueden ser consultados en las fuentes de origen, se evalúa la rentabilidad del proyecto en el presente. Luego, para revisar la diferencia de ganancia, se toma como referencia el valor de los terrenos similares y cercanos al del proyecto y los departamentos nuevos para el año 2010, un año antes del anuncio de las estaciones de la Línea 3 de Metro, de tal manera de registrar su valor en UF antes y que tanta diferencia ostentan ante un modelo de valoración de suelo e inmuebles reajustado al crecimiento económico del país.

Del resultado, se resta la diferencia entre valor 2010 y valor 2019, para así conocer qué tanto incrementó el valor y poder simular el valor potencial de la recuperación de plusvalía que se podría aplicar tanto al terreno como a los departamentos. Tomando el modelo colombiano de recuperación de plusvalía (Smolka Y Furtado, 2001; Vejarano, 2008), se aplica una recaptura sobre ganancias de $50 \%$ a la transacción del terreno y de 30\% a los valores de venta de los departamentos. Este procedimiento se aplicó a cada uno de los 40 proyectos analizados.

\subsection{Técnica de análisis}

En total, se tuvo acceso a 56 proyectos desarrollados o en venta en un radio de 400 metros a la redonda desde las nuevas estaciones de metro de la Línea 3. Algunas estaciones como Los Libertadores, Cardenal Caro, Plaza de Armas, Universidad de Chile y Fernando Castillo Velasco no se

ACE, 14 (42) CC BY-ND 3.0 ES | UPC Barcelona, España | Simulación de recuperación de plusvalía urbana para Línea 3 del Metro de Santiago. DOI: http://dx.doi.org/10.5821/ace.14.42.8963 
encontraron proyectos para su análisis. Por otro lado, se descubrieron algunas inconsistencias y falta de datos completos para 16 proyectos, que fueron desechados para esta evaluación.

El valor actual neto es un procedimiento que calcula el valor presente de un determinado número de flujos financieros futuros generados por una inversión en base a datos obtenidos como se indica en Tabla 3. Se calcula aplicando una tasa de descuento al momento actual todos los flujos futuros, simulando cuál serían las ganancias si dichos flujos se trajeran al presente, para comparar estas ganancias con la inversión inicial. La tasa de descuento (d) es el resultado del producto entre el coste medio ponderado de capital (CMPC) y la tasa de inflación del periodo. Para estos proyectos, se ha aplicado una tasa de descuento del $12 \%^{2}$. Se considera que si el VAN es mayor a 0 (es decir, supera la inversión inicial), el proyecto es una inversión recomendable. De esta manera, se puede evaluar la aplicación de recuperación de plusvalía desde una mirada que permita identificar si el mercado inmobiliario resulta muy perjudicado.

La fórmula del VAN es:

$$
V A N=\sum_{i}^{n}-I+\frac{R\left[1-(1+i)^{-n}\right]}{i}
$$

Donde,

$\mathrm{R}=$ Flujo neto de dinero

$\mathrm{n}=$ periodos a evaluar

$\mathrm{i}=$ Tasa de Descuento $(12 \%)$

Tabla 3. Ficha de Datos para Evaluación de los proyectos según origen de datos

\begin{tabular}{|c|c|}
\hline Dato & Fuente \\
\hline Tamaño Predial (m2) & $\begin{array}{l}\text { Conservador de Bienes Raíces de Santiago mediante } \\
\text { InCiti.com }\end{array}$ \\
\hline Valor Total de Suelo (UF) & $\begin{array}{l}\text { Conservador de Bienes Raíces de Santiago mediante } \\
\text { InCiti.com }\end{array}$ \\
\hline Valor de Suelo (UF/m2) & $\begin{array}{l}\text { Conservador de Bienes Raíces de Santiago mediante } \\
\text { InCiti.com }\end{array}$ \\
\hline Pisos del edificio (n) & Expediente del proyecto de InCiti.com \\
\hline $\begin{array}{l}\text { Unidades de Departamentos } \\
\text { en Venta }(n)\end{array}$ & Expediente del proyecto de InCiti.com \\
\hline $\begin{array}{l}\text { Superficie promedio de los } \\
\text { departamentos (m2) }\end{array}$ & Expediente del proyecto de InCiti.com \\
\hline $\begin{array}{l}\text { Superficie Construida sobre } \\
\text { nivel } 0 \text { del edificio (m2) }\end{array}$ & $\begin{array}{l}\text { Estimación a partir de exigencias del Plan Regulador Comunal } \\
\text { Vigente en Santiago Centro }\end{array}$ \\
\hline $\begin{array}{l}\text { Superficie Construida } \\
\text { Subterráneos del edificio (m2) }\end{array}$ & $\begin{array}{l}\text { Estimación a partir de cantidad de estacionamientos y tamaño } \\
\text { predial }\end{array}$ \\
\hline $\begin{array}{l}\text { Superficie de departamentos } \\
\text { en venta }(\mathrm{m} 2)\end{array}$ & Expediente del proyecto de InCiti.com \\
\hline $\begin{array}{l}\text { Cantidad de } \\
\text { estacionamientos en Venta } \\
\text { (n) }\end{array}$ & Expediente del proyecto de InCiti.com \\
\hline $\begin{array}{l}\text { Cantidad de Bodegas en } \\
\text { Venta (n) }\end{array}$ & Expediente del proyecto de InCiti.com \\
\hline
\end{tabular}

\footnotetext{
2 Para el análisis de estos proyectos, existe una recomendación implícita de considerar una tasa entre un 10\% al 18\%, de forma conservadora. Si bien este valor depende del inversionista, se consideró parejo para todos los proyectos analizados.
}

ACE, 14 (42) CC BY-ND 3.0 ES | UPC Barcelona, España | Simulación de recuperación de plusvalía urbana para Línea 3 del Metro de Santiago. DOI: http://dx.doi.org/10.5821/ace.14.42.8963 


\begin{tabular}{|l|l|}
\hline Superficie Construida (m2) & Expediente del proyecto de InCiti.com \\
\hline $\begin{array}{l}\text { Valor de Venta de } \\
\text { Departamentos (UF/m2) }\end{array}$ & Portalinmobiliario, Toctoc.com y sitio web de empresa \\
\hline $\begin{array}{l}\text { Valor Venta de } \\
\text { Estacionamientos (UF) }\end{array}$ & Expediente del proyecto de InCiti.com \\
\hline Valor Venta de Bodegas (UF) & Expediente del proyecto de InCiti.com \\
\hline Inversión Inicial (UF) & - \\
\hline Ingresos (UF) & - \\
\hline
\end{tabular}

Fuente: Elaboración de los autores.

A modo de síntesis, la evaluación de los costos totales de construcción se ha realizado siguiendo el modelo de estructura de costos presentado por el Dr. Julio Aznares (Simian y Niklitschek, 2017). La Tabla 4 sintetiza dicha estructura de costos y detalla cómo se han obtenido los datos.

Tabla 4. Estructura de costos para evaluar los proyectos

\begin{tabular}{|c|c|c|}
\hline Item & valor & Fuente \\
\hline 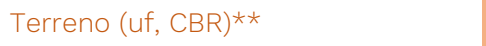 & Unitario & Conservador de Bienes Raíces de Santiago \\
\hline $\begin{array}{l}\text { Costo construcción sobre } 0 \\
\text { (uf) }{ }^{\star \star \star}\end{array}$ & 22 & $\begin{array}{l}\text { Estimación desarrollada por el Servicio de } \\
\text { Impuestos Internos }\end{array}$ \\
\hline 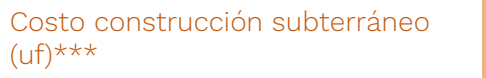 & 15 & $\begin{array}{l}\text { Estimación desarrollada por el Servicio de Impuestos } \\
\text { Internos }\end{array}$ \\
\hline $\begin{array}{l}\text { Derechos municipales }(0,12 \\
u f / m 2)^{\star \star \star \star}\end{array}$ & 0,11 & Ley General de Urbanismo y Construcciones \\
\hline $\begin{array}{l}\text { Estudio arquitectura e ingeniería } \\
\text { (sobre costo de construcción)* }\end{array}$ & 0,05 & $\begin{array}{l}\text { Aranceles Referenciales del Colegio de Arquitectos } \\
\text { de Chile }\end{array}$ \\
\hline Estudio cálculo (uf/m2)* & 0,2 & $\begin{array}{l}\text { Aranceles Referenciales del Colegio de Arquitectos } \\
\text { de Chile }\end{array}$ \\
\hline Paisajismo (obras, uf/m2) & 2,5 & $\begin{array}{l}\text { Aranceles Referenciales del Colegio de Arquitectos } \\
\text { de Chile }\end{array}$ \\
\hline 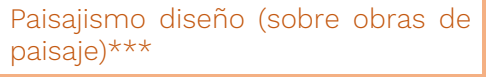 & 0,04 & $\begin{array}{l}\text { Aranceles Referenciales del Colegio de Arquitectos } \\
\text { de Chile }\end{array}$ \\
\hline $\begin{array}{l}\text { Administración } \quad \text { (costos } \quad \text { de } \\
\text { construcción)* }\end{array}$ & 0,02 & $\begin{array}{l}\text { Aranceles Referenciales del Colegio de Arquitectos } \\
\text { de Chile }\end{array}$ \\
\hline $\begin{array}{l}\text { Marketing y ventas (sobre } \\
\text { construcción) }\end{array}$ & 0,08 & Aznares en Simian et al. 2017 \\
\hline Gastos legales (sobre construcción) & 0,02 & Aznares en Simian et al. 2017 \\
\hline Impuestos a la renta & 0,1 & Servicio de Impuestos Internos \\
\hline I.V.A. & 0,0665 & Servicio de Impuestos Internos \\
\hline Velocidad de venta(mes)***** & 36 & Cámara Chilena de la Construcción \\
\hline
\end{tabular}

Fuente: Elaboración de los Autores.

\section{Resultados}

Se realizó la evaluación sistemática de 40 proyectos (Figura 4) para conocer cuál sería su rentabilidad bruta presunta en relación a su evaluación inicial, en relación a cada m2 comercializado y su diferencia con el valor antes de conocerse la construcción de estaciones de metro.

ACE, 14 (42) CC BY-ND 3.0 ES | UPC Barcelona, España | Simulación de recuperación de plusvalía urbana para Línea 3 del

Metro de Santiago. DOI: http://dx.doi.org/10.5821/ace.14.42.8963 
Figura 4. Localización de proyectos inmobiliarios evaluados en un radio de $400 \mathrm{~m}$. desde las estaciones de la Línea 3 de Metro

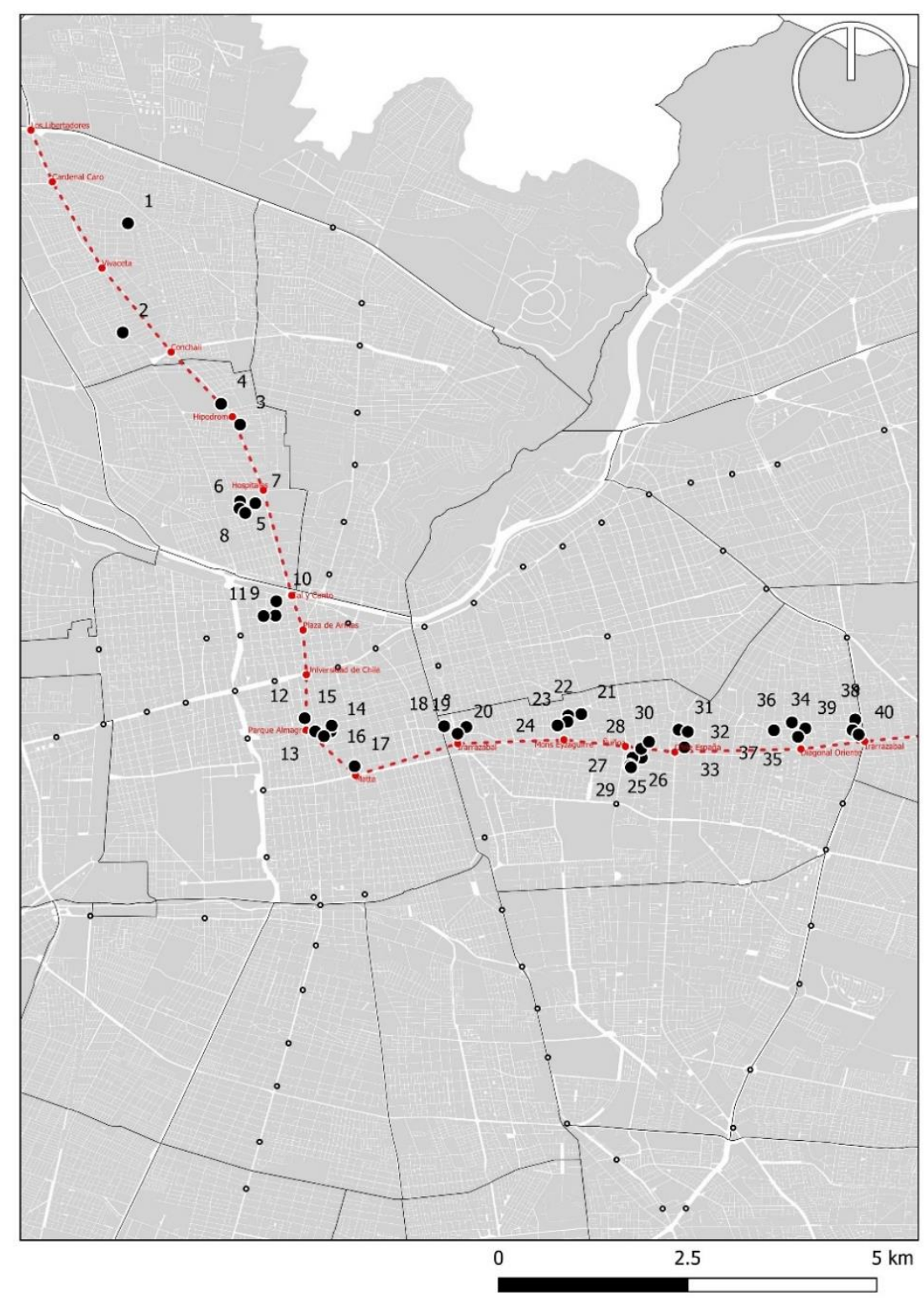

Fuente: Elaboración de los autores.

En la Tabla 5 se sintetizan las ganancias esperadas para los proyectos analizados en torno a las estaciones de la Línea 3.

En promedio, los proyectos evaluados tienen 13 pisos, con ganancias esperadas según VAN de 4.97 millones de Euros (UF 139,664) y la suma del VAN de los 40 proyectos evaluados entera 198.7 millones de Euros (UF 5.585.308). 
Tabla 5. Rentabilidad de proyectos inmobiliarios en torno a la Línea 3 del Metro de Santiago, medidos por VAN

\begin{tabular}{|c|c|c|c|c|c|c|c|c|c|c|c|}
\hline Proyecto & $\begin{array}{c}\text { Estación } \\
\text { de metro } \\
\text { cercana } \\
(400 \mathrm{~m})\end{array}$ & Comuna & Pisos & $\begin{array}{c}\text { Costo } \\
\text { Construcción } \\
\text { (UF) }\end{array}$ & $\begin{array}{l}\text { VENTAS } \\
\text { (UF) }\end{array}$ & $\begin{array}{l}\text { Terreno } \\
\text { (UF) }\end{array}$ & $\begin{array}{l}\text { VAN } \\
\text { (UF) }\end{array}$ & VAN Euros & $\begin{array}{l}\text { Terreno } \\
\text { sobre } \\
\text { VENTAS }\end{array}$ & $\begin{array}{l}\text { VAN } \\
\text { sobre } \\
\text { VENTAS }\end{array}$ & $\begin{array}{l}\text { Costo } \\
\text { sobre } \\
\text { VENTAS }\end{array}$ \\
\hline 1 & Vivaceta & Conchalí & 5 & $35.928^{-}$ & 63.117 & $\begin{array}{r}- \\
5.572\end{array}$ & 4.825 & 171.612 & 0,088 & 0,076 & 0,569 \\
\hline 2 & Conchali & Conchalí & 14 & $\begin{array}{r}- \\
403.733\end{array}$ & 705.316 & $\begin{array}{c}- \\
58.226\end{array}$ & 57.165 & 2.033 .344 & 0,083 & 0,081 & 0,572 \\
\hline 3 & $\begin{array}{c}\text { Plaza } \\
\text { Chacabuco }\end{array}$ & Independencia & 12 & $\begin{array}{c}- \\
246.272\end{array}$ & 441.234 & $\begin{array}{c}- \\
36.710\end{array}$ & 42.139 & 1.498 .884 & 0,083 & 0,096 & 0,558 \\
\hline 4 & $\begin{array}{c}\text { Plaza } \\
\text { Chacabuco }\end{array}$ & Independencia & 17 & $\begin{array}{c}- \\
389.242\end{array}$ & 689.158 & $\begin{array}{c}- \\
23.749\end{array}$ & 90.633 & 3.223 .783 & 0,034 & 0,132 & 0,565 \\
\hline 5 & Hospitales & Independencia & 23 & $\begin{array}{r}- \\
464.172\end{array}$ & 989.982 & $\begin{array}{c}- \\
286.730\end{array}$ & 10.008 & 355.981 & 0,290 & 0,010 & 0,469 \\
\hline 6 & Hospitales & Independencia & 23 & $\begin{array}{c}- \\
750.349\end{array}$ & 1.399.977 & $\begin{array}{c}- \\
39.569\end{array}$ & 237.235 & 8.438 .368 & 0,028 & 0,169 & 0,536 \\
\hline 7 & Hospitales & Independencia & 25 & $\begin{array}{r}- \\
779.286\end{array}$ & 1.289.521 & $\begin{array}{c}- \\
21.390\end{array}$ & 132.935 & 4.728 .443 & 0,017 & 0,103 & 0,604 \\
\hline 8 & Hospitales & Independencia & 15 & $\begin{array}{r}- \\
303.568\end{array}$ & 520.416 & $\begin{array}{c}- \\
12.461\end{array}$ & 63.003 & 2.240 .993 & 0,024 & 0,121 & 0,583 \\
\hline 9 & $\begin{array}{l}\text { Cal y } \\
\text { Canto }\end{array}$ & Santiago & 14 & $\begin{array}{r}- \\
420.738\end{array}$ & 1.066 .160 & $\begin{array}{c}- \\
133.209\end{array}$ & 256.148 & 9.111 .093 & 0,125 & 0,240 & 0,395 \\
\hline 10 & $\begin{array}{l}\text { Cal y } \\
\text { Canto }\end{array}$ & Santiago & 6 & 112.500 & 218.594 & $\begin{array}{c}- \\
29.286\end{array}$ & 21.687 & 771.403 & 0,134 & 0,099 & 0,515 \\
\hline 11 & $\begin{array}{l}\text { Cal y } \\
\text { Canto }\end{array}$ & Santiago & 16 & $\begin{array}{r}- \\
571.057\end{array}$ & 950.602 & $\begin{array}{c}- \\
68.896\end{array}$ & 55.273 & 1.966 .040 & 0,072 & 0,058 & 0,601 \\
\hline 12 & $\begin{array}{l}\text { Parque } \\
\text { Almagro }\end{array}$ & Santiago & 9 & $\begin{array}{c}- \\
232.895\end{array}$ & 583.188 & $\begin{array}{c}- \\
117.441\end{array}$ & 97.117 & 3.454 .425 & 0,201 & 0,167 & 0,399 \\
\hline 13 & $\begin{array}{l}\text { Parque } \\
\text { Almagro }\end{array}$ & Santiago & 12 & $\begin{array}{r}- \\
819.799\end{array}$ & 1.849 .018 & $\begin{array}{c}- \\
161.122\end{array}$ & 407.348 & 14.489 .225 & 0,087 & 0,220 & 0,443 \\
\hline 14 & $\begin{array}{l}\text { Parque } \\
\text { Almagro }\end{array}$ & Santiago & 12 & $\begin{array}{c}- \\
394.258\end{array}$ & 801.548 & $\begin{array}{c}- \\
89.134\end{array}$ & 116.133 & 4.130 .809 & 0,111 & 0,145 & 0,492 \\
\hline 15 & $\begin{array}{l}\text { Parque } \\
\text { Almagro }\end{array}$ & Santiago & 12 & $\begin{array}{r}- \\
323.774\end{array}$ & 612.561 & $\begin{array}{c}- \\
47.000\end{array}$ & 81.728 & 2.907 .049 & 0,077 & 0,133 & 0,529 \\
\hline 16 & $\begin{array}{l}\text { Parque } \\
\text { Almagro }\end{array}$ & Santiago & 39 & $\begin{array}{c}- \\
448.686 \\
\end{array}$ & 850.200 & $\begin{array}{c}- \\
152.400 \\
\end{array}$ & 37.938 & 1.349 .441 & 0,179 & 0,045 & 0,528 \\
\hline 17 & Matta & Santiago & 23 & $\begin{array}{c}- \\
588.494 \\
\end{array}$ & 1.084 .523 & $\begin{array}{c}- \\
101.328 \\
\end{array}$ & 112.491 & 4.001 .270 & 0,093 & 0,104 & 0,543 \\
\hline 18 & Irarrazabal & Ñuñoa & 7 & $\begin{array}{r}- \\
146.303 \\
\end{array}$ & 333.007 & $\begin{array}{c}- \\
80.869 \\
\end{array}$ & 28.421 & 1.010 .920 & 0,243 & 0,085 & 0,439 \\
\hline 19 & Irarrazabal & Ñuñoa & 21 & $\begin{array}{r}- \\
319.589\end{array}$ & 860.505 & 225.360 & 124.083 & 4.413 .591 & 0,262 & 0,144 & 0,371 \\
\hline 20 & Irarrazabal & Ñuñoa & 33 & 653.690 & 1.754 .583 & $\begin{array}{c}- \\
89.615 \\
\end{array}$ & 581.065 & 20.668 .255 & 0,051 & 0,331 & 0,373 \\
\hline 21 & $\begin{array}{l}\text { Monseñor } \\
\text { Eyzaguirre }\end{array}$ & Ñuñoa & 7 & $\begin{array}{r}- \\
162.200\end{array}$ & 422.870 & $\begin{array}{c}- \\
85.200\end{array}$ & 78.118 & 2.778 .617 & 0,201 & 0,185 & 0,384 \\
\hline 22 & $\begin{array}{l}\text { Monseñor } \\
\text { Eyzaguirre }\end{array}$ & Ñuñoa & 12 & $\begin{array}{r}- \\
353.156 \\
\end{array}$ & 903.761 & $\begin{array}{c}- \\
135.500 \\
\end{array}$ & 200.731 & 7.139 .923 & 0,150 & 0,222 & 0,391 \\
\hline 23 & $\begin{array}{l}\text { Monseñor } \\
\text { Eyzaguirre }\end{array}$ & Ñuñoa & 12 & $\begin{array}{r}- \\
321.978\end{array}$ & 805.221 & $\begin{array}{c}- \\
121.551\end{array}$ & 170.154 & 6.052 .304 & 0,151 & 0,211 & 0,400 \\
\hline 24 & $\begin{array}{l}\text { Monseñor } \\
\text { Eyzaguirre }\end{array}$ & Ñuñoa & 7 & 239.394 & 553.021 & $\begin{array}{c}- \\
51.503\end{array}$ & 125.437 & 4.461 .753 & 0,093 & 0,227 & 0,433 \\
\hline 25 & Ñuñoa & Ñuñoa & 16 & $\begin{array}{r}- \\
353.826\end{array}$ & 927.515 & $\begin{array}{c}- \\
171.413\end{array}$ & 187.162 & 6.657 .287 & 0,185 & 0,202 & 0,381 \\
\hline 26 & Ñuñoa & Ñuñoa & 8 & $\begin{array}{c}- \\
209.575\end{array}$ & 531.808 & $\begin{array}{c}- \\
101.501\end{array}$ & 97.026 & 3.451 .187 & 0,191 & 0,182 & 0,394 \\
\hline 27 & Ñuñoa & Ñuñoa & 8 & $\begin{array}{c}- \\
169.024\end{array}$ & 432.739 & $\begin{array}{c}- \\
86.312 \\
\end{array}$ & 77.097 & 2.742 .328 & 0,199 & 0,178 & 0,391 \\
\hline 28 & Ñuñoa & Ñuñoa & 16 & $\begin{array}{c}- \\
265.859\end{array}$ & 663.284 & $\begin{array}{c}- \\
103.250\end{array}$ & 136.721 & 4.863.112 & 0,156 & 0,206 & 0,401 \\
\hline 29 & Ñuñoa & Ñuñoa & 7 & $\begin{array}{c}- \\
380.952\end{array}$ & 908.682 & $\begin{array}{c}- \\
86.312\end{array}$ & 218.246 & 7.762 .926 & 0,095 & 0,240 & 0,419 \\
\hline 30 & Ñuñoa & Ñuñoa & 18 & 363.834 & 786.734 & $\begin{array}{c}- \\
45.953\end{array}$ & 176.980 & 6.295 .124 & 0,058 & 0,225 & 0,462 \\
\hline 31 & $\begin{array}{l}\text { Chile } \\
\text { España }\end{array}$ & Ñuñoa & 7 & -311.927 & 750.041 & $\begin{array}{c}- \\
137.224\end{array}$ & 124.169 & 4.416 .650 & 0,183 & 0,166 & 0,416 \\
\hline 32 & $\begin{array}{l}\text { Chile } \\
\text { España }\end{array}$ & Ñuñoa & 7 & $\begin{array}{c}- \\
427.889\end{array}$ & 1.171 .967 & 54.981 & 402.498 & 14.316 .699 & 0,047 & 0,343 & 0,365 \\
\hline 33 & $\begin{array}{c}\text { Chile } \\
\text { España }\end{array}$ & Ñuñoa & 16 & 282.002 & 679.770 & $\begin{array}{c}- \\
64.370\end{array}$ & 166.805 & 5.933 .196 & 0,095 & 0,245 & 0,415 \\
\hline 34 & Villa Frei & Ñuñoa & 5 & $\begin{array}{c}- \\
103.006\end{array}$ & 255.264 & $\begin{array}{c}- \\
52.100\end{array}$ & 40.952 & 1.456 .665 & 0,204 & 0,160 & 0,404 \\
\hline
\end{tabular}




\begin{tabular}{|c|c|c|c|c|c|c|c|c|c|c|c|}
\hline 35 & Villa Frei & Ñuñoa & 6 & $96.388^{-}$ & 216.787 & $\begin{array}{c}- \\
50.116\end{array}$ & 19.646 & 698.793 & 0,231 & 0,091 & 0,445 \\
\hline 36 & Villa Frei & Ñuñoa & 5 & $\begin{array}{r}- \\
144.981\end{array}$ & 381.191 & $\begin{array}{c}- \\
56.654\end{array}$ & 89.885 & 3.197 .188 & 0,149 & 0,236 & 0,380 \\
\hline 37 & Villa Frei & Ñuñoa & 5 & $\begin{array}{r}- \\
144.440\end{array}$ & 351.514 & $\begin{array}{c}- \\
24.820\end{array}$ & 95.212 & 3.386 .651 & 0,071 & 0,271 & 0,411 \\
\hline 38 & $\begin{array}{l}\text { Plaza } \\
\text { Egaña }\end{array}$ & Ñuñoa & 10 & $\begin{array}{r}- \\
145.516\end{array}$ & 296.328 & $\begin{array}{c}- \\
60.147\end{array}$ & 18.900 & 672.250 & 0,203 & 0,064 & 0,491 \\
\hline 39 & $\begin{array}{l}\text { Plaza } \\
\text { Egaña }\end{array}$ & Ñuñoa & 7 & $\begin{array}{r}- \\
350.837\end{array}$ & 910.721 & $\begin{array}{c}- \\
75.639\end{array}$ & 262.733 & 9.345 .308 & 0,083 & 0,288 & 0,385 \\
\hline 40 & $\begin{array}{l}\text { Plaza } \\
\text { Egaña }\end{array}$ & Ñuñoa & 18 & $\begin{array}{r}- \\
481.630\end{array}$ & 1.298 .344 & $\begin{array}{c}- \\
169.159\end{array}$ & 340.737 & 12.119 .892 & 0,130 & 0,262 & 0,371 \\
\hline
\end{tabular}

Fuente: elaboración de los autores en base a datos del Conservador de Bienes Raíces de Santiago, InCiti.com y Servicio de Evaluación Ambiental del Ministerio de Medio Ambiente.

De la Tabla 6 se puede revisar que no necesariamente un alto valor de suelo se relaciona a las rentabilidades obtenidas ni con el precio de la vivienda. Al tratar de comprender el peso determinante de los componentes sobre las ventas del proyecto, se observa que es estadísticamente significativa la cantidad de pisos del edificio, junto con la rentabilidad medida en el VAN, quedando en tercer orden el peso del terreno. En la estructura de costos de los proyectos evaluados, el peso del terreno, en promedio, ostenta un $12.9 \%$ contra las ventas, mientras el van asciende a 16.9\%. Sin dudas, el factor de mayor pesa sobre las ganancias por ventas son los costos de construcción, llegando a $45,6 \%$ del total de ventas.

Tabla 6. Evaluación de factores sobre ventas del proyecto

\begin{tabular}{|c|c|c|c|c|c|c|}
\hline \multicolumn{7}{|c|}{ Evaluación de factores sobre ventas del proyecto ; Y $=$ Ventas } \\
\hline $\begin{array}{c}\text { Estadísticas de la regresión } \\
\begin{array}{c}\text { Coeficiente de } \\
\text { correlación múltiple }\end{array}\end{array}$ & 0,914 & (Intercepción) & 100198,847 & 62230,256 & 1,61013 & 0,11610434636375 \\
\hline $\begin{array}{c}\text { Coeficiente de } \\
\text { determinación R^2 }\end{array}$ & 0,835 & Terreno & 1,043 & 0,492 & 2,12015 & 0,04095326956455 \\
\hline$R^{\wedge}$ ajustado & 0,821 & VAN* & 2,233 & 0,230 & 9,69954 & 0,00000000001395 \\
\hline Error típico & 170185,185 & Pisos** & 18995,858 & 3803,738 & 4,99400 & 0,00001530205702 \\
\hline & & & $* \star$ Mayor significación; * Valor significativo \\
\hline
\end{tabular}

Fuente: Elaboración propia.

La inversión en construcción de la Línea 3 del Metro de Santiago consistió en un monto de 1.380 millones de Euros actuales (EMB, 2011). Según los datos de la Tabla 6, con una recuperación de plusvalía del $50 \%$ a las ganancias por ventas de terrenos y de 30\% a la comercialización de las viviendas, aplicado únicamente a los proyectos evaluados en este ejercicio hipotético, podría recaudar un equivalente al $41 \%$ de la inversión total original en esta nueva infraestructura, o bien para la compra de 4,151 unidades de vivienda pública ubicadas en el radio de 400 metros evaluados para cada una de las nuevas estaciones que ha revisado el presente estudio.

Finalmente, se evalúa el impacto sobre el mercado inmobiliario de la recuperación de plusvalía sobre viviendas nuevas y el resultado se sintetiza en la siguiente tabla. 
Tabla 7. Evaluación de recuperación de plusvalías aplicada a los 40 proyectos evaluados

\begin{tabular}{|c|c|c|c|c|c|c|c|c|c|c|c|}
\hline Prom. & $\begin{array}{l}\text { Estación } \\
\text { de metro } \\
\text { cercana } \\
(400 \mathrm{~m})\end{array}$ & $\begin{array}{l}\text { Venta } \\
\text { (UF/m2) }\end{array}$ & $\begin{array}{l}\text { Valor } \\
\text { de } \\
\text { Suelo } \\
\text { (UF/m2) }\end{array}$ & $\begin{array}{l}\text { UF/m2 } \\
\text { Suelo } \\
2010\end{array}$ & $\begin{array}{l}\text { UF/m2 } \\
\text { depts. } \\
2010\end{array}$ & $\begin{array}{l}\text { Difer. } \\
\text { valor de } \\
\text { Suelo } \\
\text { (UF/m2) }\end{array}$ & $\begin{array}{l}\text { Difer. } \\
\text { valor } \\
\text { depts. } \\
\text { (UF/m2) }\end{array}$ & $\begin{array}{l}\text { Recuperación } \\
\text { por venta } \\
\text { de suelos } \\
\text { UF (50\%) }\end{array}$ & $\begin{array}{c}\text { Recuperación } \\
\text { por venta } \\
\text { depts. UF } \\
(30 \%)\end{array}$ & $\begin{array}{c}\text { Captura } \\
\text { Total en } \\
\text { Euros }\end{array}$ & $\begin{array}{l}\text { VAN con } \\
\text { recuperación } \\
\text { de plusvalías } \\
\text { en Euros }\end{array}$ \\
\hline 1 & Vivaceta & 52,20 & 6,19 & 4,00 & 15,70 & 2,19 & 36,50 & 986 & 11.931 & 424.387 & -163.951 \\
\hline 2 & Conchalí & 57,30 & 9,00 & 4,90 & 19,80 & 4,10 & 37,50 & 13.264 & 417.746 & 14.859 .092 & -1.491 .388 \\
\hline 3 & $\begin{array}{c}\text { Plaza } \\
\text { Chacabuco }\end{array}$ & 59,10 & 26,70 & 7,30 & 30,80 & 19,40 & 28,30 & 13.339 & 186.791 & 6.644 .113 & -77.167 \\
\hline 4 & $\begin{array}{c}\text { Plaza } \\
\text { Chacabuco }\end{array}$ & 58,40 & 10,34 & 5,20 & 26,40 & 5,14 & 32,00 & 5.905 & 332.717 & 11.834 .618 & 416.487 \\
\hline 5 & Hospitales & 62,30 & 58,21 & 8,30 & 39,40 & 49,91 & 22,90 & 122.922 & 329.107 & 11.706 .379 & -2.420 .860 \\
\hline 6 & Hospitales & 61,60 & 28,26 & 8,20 & 39,00 & 20,06 & 22,60 & 14.045 & 458.540 & 16.310 .127 & 4.569 .435 \\
\hline 7 & Hospitales & 55,30 & 11,88 & 6,60 & 22,70 & 5,28 & 32,60 & 4.755 & 669.197 & 23.803 .071 & -917.900 \\
\hline 8 & Hospitales & 55,80 & 12,46 & 7,80 & 22,30 & 4,66 & 33,50 & 2.331 & 278.720 & 9.913 .968 & -110.706 \\
\hline 9 & Cal y Canto & 86,20 & 56,59 & 37,11 & 32,90 & 19,48 & 53,30 & 22.929 & 604.609 & 21.505 .726 & 4.009.711 \\
\hline 10 & Cal y Canto & 63,80 & 48,81 & 26,85 & 30,90 & 21,96 & 32,90 & 6.589 & 101.750 & 3.619.211 & -87.110 \\
\hline 11 & Cal y Canto & 53,90 & 29,27 & 13,76 & 31,30 & 15,51 & 22,60 & 18.257 & 351.035 & 12.486 .187 & -995.812 \\
\hline 12 & $\begin{array}{c}\text { Parque } \\
\text { Almagro }\end{array}$ & 85,70 & 75,82 & 45,30 & 34,00 & 30,52 & 51,70 & 23.636 & 320.871 & 11.413 .285 & 747.078 \\
\hline 13 & $\begin{array}{c}\text { Parque } \\
\text { Almagro }\end{array}$ & 75,70 & 34,43 & 14,10 & 33,00 & 20,33 & 42,70 & 47.567 & 965.208 & 34.332 .138 & 6.345 .288 \\
\hline 14 & $\begin{array}{c}\text { Parque } \\
\text { Almagro }\end{array}$ & 67,00 & 52,37 & 28,60 & 36,80 & 23,77 & 30,20 & 20.228 & 327.670 & 11.655 .123 & 1.366 .095 \\
\hline 15 & $\begin{array}{c}\text { Parque } \\
\text { Almagro }\end{array}$ & 63,70 & 28,94 & 19,20 & 40,00 & 9,74 & 23,70 & 7.910 & 199.618 & 7.100 .346 & 1.222 .773 \\
\hline 16 & $\begin{array}{c}\text { Parque } \\
\text { Almagro }\end{array}$ & 62,20 & 100,00 & 50,70 & 30,30 & 49,30 & 31,90 & 37.567 & 399.024 & 14.193 .192 & -2.017 .325 \\
\hline 17 & Matta & 61,60 & 24,00 & 13,30 & 21,00 & 10,70 & 40,60 & 22.588 & 642.629 & 22.858 .097 & -1.420 .909 \\
\hline 18 & Irarrázaval & 77,20 & 56,20 & 22,50 & 33,00 & 33,70 & 44,20 & 24.246 & 175.032 & 6.225 .852 & -465.912 \\
\hline 19 & Irarrázaval & 91,50 & 60,00 & 46,80 & 34,50 & 13,20 & 57,00 & 24.790 & 501.230 & 17.828 .574 & 184.469 \\
\hline 20 & Irarrázaval & 90,60 & 50,00 & 17,00 & 35,00 & 33,00 & 55,60 & 29.573 & \#\#\#\#\#\# & 35.635 .294 & 12.215 .190 \\
\hline 21 & $\begin{array}{l}\text { Monseñor } \\
\text { Eyzaguirre }\end{array}$ & 87,10 & 71,00 & 26,70 & 50,00 & 44,30 & 37,10 & 26.580 & 166.575 & 5.925 .053 & 1.373 .138 \\
\hline 22 & $\begin{array}{l}\text { Monseñor } \\
\text { Eyzaguirre }\end{array}$ & 87,80 & 55,83 & 17,10 & 45,80 & 38,73 & 42,00 & 46.999 & 397.068 & 14.123.617 & 3.789 .663 \\
\hline 23 & $\begin{array}{l}\text { Monseñor } \\
\text { Eyzaguirre }\end{array}$ & 84,70 & 43,06 & 16,50 & 55,90 & 26,56 & 28,80 & 37.486 & 251.312 & 8.939 .108 & 3.931 .863 \\
\hline 24 & $\begin{array}{l}\text { Monseñor } \\
\text { Eyzaguirre }\end{array}$ & 76,70 & 15,72 & 13,20 & 41,50 & 2,52 & 35,20 & 4.130 & 234.615 & 8.345 .173 & 2.482 .190 \\
\hline 25 & Ñuñoa & 88,40 & 66,91 & 20,80 & 36,40 & 46,11 & 52,00 & 59.062 & 505.362 & 17.975 .609 & 2.393.297 \\
\hline 26 & Ñuñoa & 85,30 & 70,00 & 35,00 & 35,60 & 35,00 & 49,70 & -25.375 & 287.018 & 10.209 .071 & 1.029 .478 \\
\hline 27 & Ñuñoa & 87,60 & 40,00 & 17,10 & 34,80 & 22,90 & 52,80 & 24.705 & 239.944 & 8.534 .760 & 717.799 \\
\hline 28 & Ñuñoa & 84,00 & 70,00 & 35,00 & 43,10 & 35,00 & 40,90 & 25.813 & 295.952 & 10.526 .947 & 2.366 .014 \\
\hline 29 & Ñuñoa & 79,60 & 61,65 & 20,80 & 39,10 & 40,85 & 40,50 & 28.596 & 426.716 & 15.178 .166 & 4.162 .510 \\
\hline 30 & Ñuñoa & 72,00 & 22,87 & 5,20 & 36,90 & 17,67 & 35,10 & 17.753 & 355.258 & 12.636 .401 & 3.297 .639 \\
\hline 31 & $\begin{array}{c}\text { Chile } \\
\text { España }\end{array}$ & 79,60 & 40,14 & 10,70 & 36,10 & 29,44 & 43,50 & 50.320 & 378.554 & 13.465 .100 & 1.222 .599 \\
\hline 32 & $\begin{array}{c}\text { Chile } \\
\text { España }\end{array}$ & 91,30 & 39,99 & 11,25 & 28,90 & 28,74 & 62,40 & 19.756 & 746.454 & 26.551 .102 & 8.018 .499 \\
\hline
\end{tabular}




\section{ACE Architecture, City and Environment}

\begin{tabular}{|l|c|r|r|r|r|r|r|r|r|r|r|}
\hline 33 & $\begin{array}{c}\text { Chile } \\
\text { España }\end{array}$ & 80,00 & 43,91 & 14,50 & 32,00 & 29,41 & 48,00 & 21.557 & 375.648 & 13.361 .684 & 2.763 .667 \\
\hline 34 & Villa Frei & 82,30 & 35,96 & 17,30 & 37,30 & 18,66 & 45,00 & 13.516 & 129.600 & 4.609 .840 & 363.165 \\
\hline 35 & Villa Frei & 73,90 & 41,66 & 21,60 & 31,60 & 20,06 & 42,30 & 12.066 & 113.956 & 4.053 .394 & -262.712 \\
\hline 36 & Villa Frei & 87,30 & 38,38 & 19,30 & 26,80 & 19,08 & 60,50 & 14.084 & 246.332 & 8.761 .946 & 1.118 .764 \\
\hline 37 & Villa Frei & 81,80 & 33,81 & 19,00 & 26,10 & 14,81 & 55,70 & 5.437 & 219.040 & 7.791 .185 & 1.538 .500 \\
\hline 38 & $\begin{array}{c}\text { Plaza } \\
\text { Egaña }\end{array}$ & 67,00 & 52,67 & 16,90 & 47,20 & 35,77 & 19,80 & 20.424 & 79.087 & 2.813 .125 & 4.953 \\
\hline 39 & $\begin{array}{c}\text { Plaza } \\
\text { Egaña }\end{array}$ & 87,30 & 40,02 & 12,30 & 46,20 & 27,72 & 41,10 & 26.196 & 396.401 & 14.099 .876 & 6.000 .674 \\
\hline 40 & $\begin{array}{c}\text { Plaza } \\
\text { Egaña }\end{array}$ & 90,20 & 67,66 & 21,30 & 40,40 & 46,36 & 49,80 & 57.955 & 668.570 & 23.780 .854 & 6.478 .836 \\
\hline
\end{tabular}

Fuente: Elaboración de los autores. Notas: Prom. = Promoción; depts. = departamentos y Difer. = Diferencia;

Se puede ver que, de 40 proyectos, luego de la recuperación, 33 siguen siendo rentables (VAN > 0) y sólo 7 caen bajo la línea de rentabilidad esperable. Es decir, el modelo de recuperación de plusvalía no necesariamente impacta el mercado inmobiliario y desde esta simulación se puede avanzar hacia mecanismos que eviten situaciones como los 7 proyectos que resultan mermados por la aplicación del instrumento, en un escenario donde una deliberación técnica inicial y democrática, avance desde simulaciones como la aquí presentada hacia soluciones óptimas para que la inversión pública no se base solo en la colocación de nuevos objetos urbanos sino también en la recuperación de parte de las rentas generadas por dichas colocaciones.

\section{Conclusiones}

El instrumento de recuperación de plusvalías por inversión pública se ha utilizado en otras naciones de América Latina y en Chile aun no existen experiencias al respecto. En este estudio, la aplicación de un sistema hipotético de captura de plusvalía arroja resultados tentadores, solo utilizando un sistema similar al ya existente en Colombia. Con los fondos recuperados y reintegrados a presupuestos de diversos municipios, infraestructuras públicas como Metro bien podrían ayudar a mejorar la ciudad no solo permitiendo la movilidad sino convirtiéndose en una herramienta de inversión en el mejoramiento de barrios más allá de sus estaciones. No obstante, las fricciones que se pueden generar ante las 4 "l” mencionadas por Smolka (ideología, interés, ignorancia e inercia), podrían entorpecer los avances de una política pública que en ha tenido buenos resultados en otras naciones de América Latina. Esto es particularmente relevante, considerando que, en Chile, el mercado de la vivienda y su desregulación están afectando la vida urbana.

Un informe de Leilani Farha, relatora especial para la vivienda de las Naciones Unidas, comenta que la mercantilización de la vivienda en Chile pone en peligro su acceso universal y que la falta de regulación del mercado inmobiliario perjudica a los hogares (Farha, 2018). El problema del acceso a la vivienda en Chile se relaciona con la desregulación, pero existen alternativas para que dichas regulaciones no sean solo sobre la industria del suelo e inmobiliaria, sino a favor del bien común. El mecanismo de la recuperación de plusvalías podría también aportar a que el Estado invierta con mayor decisión en proyectos urbanos de alto interés público, a sabiendas que parte de dicha inversión retornará una vez detonado el proceso de renovación urbana.

Chile ha sido parte de las naciones redactoras y ha suscrito la Nueva Agenda Urbana, donde el problema de la asequibilidad de la vivienda y la relación público privada para asegurar su acceso se encuentran entre los compromisos para la próxima década (United Nations, 2017). Parte de estos compromisos se encuentran inscritos en la nueva Política Nacional de Desarrollo Urbano (CNDU, 2015), proyecto que se viene discutiendo desde el año 2013 pero que avanza tímidamente. Uno de sus avances recientes ha sido el proyecto de modificación de la Ley General de Urbanismo y

ACE, 14 (42) CC BY-ND 3.0 ES | UPC Barcelona, España | Simulación de recuperación de plusvalía urbana para Línea 3 del Metro de Santiago. DOI: http://dx.doi.org/10.5821/ace.14.42.8963 
Construcciones, donde se establecen condiciones para densificar zonas estratégicas de ciudades, situación que ha despertado algunas dudas ante un excesivo poder entregado al Ministro de Vivienda y Urbanismo, quien podría decidir donde se cambia la regulación urbanística sin estar obligado a consultar a las comunidades locales y sin procesos participativos vinculantes (Bannen, Rojas, Ruiztagle y Vicuña, 2019). A nuestro entender, como parte de la creación de zonas de integración urbana, debe aparecer una ley de recuperación de plusvalías que aproveche las oportunidades que se generarán con nuevas inversiones por parte de privados, en un esquema en que todos ganen, especialmente los vecinos de dichos barrios.

\section{Autoría}

El primer autor ha redactado, conceptualizado, desarrollado los mapas y diseñado la investigación y el segundo autor ha construido las bases de datos, analizado los datos y diseñado la investigación.

Conflicto de intereses: Los autores declaran que no hay conflicto de intereses.

\section{Bibliografía}

Allard, P. y Cociña, C. (2018). Infraestructura y valor de suelo: ¿Quién se beneficia de la inversión estatal? ARQ (Santiago), 99, 148-153. DOI: https://doi.org/10.4067/s0717-69962018000200148

Alegret Burgués, A. y Cabré Puig, E. (2011). Reparto de los derechos de propiedad en la ciudad: propuesta para disponer de plusvalías socialmente sostenibles. ACE: Architecture, City and Environment, 6(17), 59-94. DOI: http://dx.doi.org/10.5821/ace.v6i17.2529

Alvarado, C.; Gómez, R. y Hidalgo, R. (2016). Expresión Territorial de la Fragmentación y Segregación. In Expresión Territorial de la Fragmentación y Segregación. Cuernavaca, México: Universidad Autónoma del Estado de Morelos.

Alvarado-Peterson, V. (2019). El bienestar en el Estado neoliberal: escenarios de la propiedad en el Gran Santiago. Cultura-Hombre-Sociedad, 29(2), 13-35. Recuperado de https://scielo.conicyt.cl/scielo.php?script=sci arttext\&pid=S0719-27892019000200013

Bannen, P.; Rojas, C.; Ruiz-tagle, J. y Vicuña, M. (2019). Observaciones y propuestas al proyecto de ley de integración social y urbana (No. 5). Recuperado de http://estudiosurbanos.uc.c//images/publicaciones/documentos-de-trabajo/Doc trabajo ley integracion.pdf

CNDU. (2015). Política Nacional de Desarrollo Urbano. Recuperado de https://cndu.gob.cl/wpcontent/uploads/2014/10/L4-Politica-Nacional-Urbana.pdf

de Grange, L. (2018). "Metro debiera no solo estar integrado con los buses, también con los taxis y los colectivos." October 1, 2019, from CPI Recuperado de http://www.infraestructurapublica.cl/louis-degrange-presidente-del-directorio-de-metro-metro-debiera-no-solo-estar-integrado-con-los-busestambien-con-los-taxis-y-los-colectivos/

EMB. (2011). Líneas 3 y 6 del Metro de Santiago. Nuevos desafíos para un mejor servicio. Revista EMB Construcción. Recuperado de http://www.emb.cl/construccion/articulo.mvc?xid=177\&tip=4\&xit=Líne as-3-y-6-del-metro-de-santiago-nuevos-desafios-para-un-mejor-servicio

ACE, 14 (42) CC BY-ND 3.0 ES | UPC Barcelona, España | Simulación de recuperación de plusvalía urbana para Línea 3 del Metro de Santiago. DOI: http://dx.doi.org/10.5821/ace.14.42.8963 
Espinoza, V. (1988). Para una historia de los pobres en la ciudad. Santiago, Chile: Ediciones SUR.

Farha, L. (2018). Report of the Special Rapporteur on adequate housing as a component of the right to an adequate standard of living, and on the right to non-discrimination in this context, on her mission to Chile. Recuperado de https://documents-dds-ny.un.org/doc/UNDOC/GEN/G18/009/43/PDF/G1800 943.pdf?OpenElement

Fundación Vivienda. (2019). Modifica la Ley General de Urbanismo y Construcciones estableciendo una reserva de suelo urbano destinada a viviendas de bajo valor. Recuperado de https://www.camara.cl/pdf.aspx?prmID=149271\&prmTIPO=DOCUMENTOCOMISION

Garreton, M. (2017). City profile: Actually existing neoliberalism in Greater Santiago. Cities, 65, 32-50. DOI: https://doi.org/10.1016/j.cities.2017.02.005

Garza, N. (2019). Spatial and Dynamic Features of Land Value Capture: A Case Study from Bogotá, Colombia. Public Finance Review, 47(3), 603-622, DOI: https://doi.org/10.1177/1091142117714551

Hidalgo-Dattwyler, R. (2019). La vivienda social en Chile y la construcción del espacio urbano en el Santiago del siglo XX. Santiago, Chile: RIL Editores.

Hutt, G. (2019). Presidente Piñera y Ministra Hutt dan inicio a construcción de la extensión de Línea 2 de Metro. Retrieved September 29, 2019, from Ministerio de Transportes y Telecomunicaciones. Recuperado de https://mtt.gob.cl/archivos/21914

Instituto Nacional de Estadísticas. (2019). Permisos de Edificación. Recuperado de https://www.ine.cl/estadisticas/economicas/construccion/edificación-superficie-autorizada

Inzulza, J. y Cárdenas, A. (2017). Desplazamiento subsidiario: efectos de gentrificación contemporánea en barrios céntricos en reconstrucción post-terremoto. Cuadernos Geográficos, 56(3), 268-291. Recuperado de https://revistaseug.ugr.es/index.php/cuadgeo/article/view/5483

Link, F., Valenzuela, F. y Fuentes, L. (2015). Segregación, estructura y composición social del territorio metropolitano en Santiago de Chile. Complejidades metodológicas en el análisis de la diferenciación social en el espacio. Revista de Geografia Norte Grande, 168(62), 151-168. DOI: http://dx.doi.org/10.4067/S0718-34022015000300009

López-Morales, E. (2016). Gentrification in Santiago, Chile: a property-led process of dispossession and exclusion. Urban Geography, 37(8), 1109-1131. DOI: https://doi.org/10.1080/02723638.2016.1149311

López-Morales, E.; Sanhueza, C.; Espinoza, S. y Órdenes, F. (2019). Verticalización inmobiliaria y valorización de renta de suelo por infraestructura pública: un análisis econométrico del Gran Santiago, 2009-2011. Eure, 45(136), 113-134. ODI: http://dx.doi.org/10.4067/S0250-71612019000300113

Miskawi, Z. (1989). An S-curve equation for project control. Construction Management and Economics. 7(2), 115-124. DOI: https://doi.org/10.1080/01446198900000016

OECD (2013). OECD Urban Policy Reviews, Chile 2013. DOI: https://doi.org/10.1787/9789264191808-en

ONU. (2017). New Urban Agenda. Recuperado de http://habitat3.org/wp-content/uploads/NUAEnglish.pdf 
Poduje, I. (2019). El fetiche de las plusvalías. Recuperado de https://cndu.gob.cl/el-fetiche-de-lasplusvalias/

Razmilic, S. A. (2010). Property values, housing subsidies and incentives: evidence from Chile's housing policies. Massachusetts Institute of Technology (MIT). Recuperado de https://dspace. mit.edu/bitstream/handle/1721.1/62112/708579235-MIT.pdf? sequence=2\&isAllowed=y

Sabatini, F.; Rasse, A.; Cáceres, G.; Robles, M. S. y Trebilcock, M. P. (2017). Promotores inmobiliarios, gentrificación y segregación residencial en Santiago de Chile. Revista Mexicana de Sociología, 79(2), 229-260. Recuperado de http://www.scielo.org.mx/scielo.php?script=sci arttext\&pid=S0188$25032017000200229 \& \operatorname{lng}=$ es\&nrm=iso

Sagredo, R. y Gazmuri, C. (2007). Historia de la vida privada en Chile. Santiago, Chile: Taurus.

Simian, J. M. y Niklitschek, V. (2017). La Industria Inmobiliaria en Chile. Evolución, desafíos y mejores prácticas. Lima, Perú: Pearson - ESE Business School, Universidad de Los Andes.

Smolka, M. (2013). Implementación de la Recuperación de Plusvalías en América Latina. Políticas e Instrumentos para el Desarrollo Urbano. Cambridge, MA, USA: Lincoln Institute of land Policy. Recuperado de http://www.lincolninst.edu/pubs/2349 Implementación-de-la-recuperación-deplusvalías-en-América-Latina--Políticas-e-instrumentos-para-el-desarrollo-urbano

Smolka, M. (2013). Seminario: 'Grandes Líneas de Politica Urbana para la promoción de la Integración Social.' Recuperado de https://politicaspublicas.uc.cl/wp-content/uploads/2015/01/2-presentacionmartim-smolka-lilp.pdf

Smolka, M. y Furtado, F. (2001). Recuperación de plusvalías en América Latina: Alternativas para el desarrollo urbano. Santiago, Chile: Eure Libros, Pontificia Universidad Católica de Chile y Lincoln Institute of Land Policy.

Valenzuela, E.; Pressacco, F.; Cienfuegos, I. y Penaglia, F. (2015). Pilares necesarios para una descentralización autónoma sin cooptación del poder central: reflexiones para el proceso descentralizador chileno. Revista de Administração Pública, 49(5), 1083-1106. DOI: https://doi.org/10.1590/0034-7612137403

Vejarano, M. C. (2008). Bogotá, D.C. Primera experiencia de recuperación de la plusvalía urbana para la colectividad, en el marco de la Ley de desarrollo territorial. ACE: Architecture, City and Environment, 3(7), 79-106. https://doi.org/10.5821/ace.v3i7.2440

Vergara-Perucich, J.-F. (2018). Aplicaciones de la teoría implosión/explosión: relación entre la Región Metropolitana de Santiago de Chile y los territorios productivos regionales. EURE-Revista de Estudios Urbano Regionales, 44(133), 71-90. Recuperado de http://eure.cl/index.php/eure/article/view/2243/1122 